\title{
The influence of DNA sequence on epigenome-induced pathologies
}

\author{
Richard B Meagher ${ }^{*}$ and Kristofer J Müssar
}

\begin{abstract}
Clear cause-and-effect relationships are commonly established between genotype and the inherited risk of acquiring human and plant diseases and aberrant phenotypes. By contrast, few such cause-and-effect relationships are established linking a chromatin structure (that is, the epitype) with the transgenerational risk of acquiring a disease or abnormal phenotype. It is not entirely clear how epitypes are inherited from parent to offspring as populations evolve, even though epigenetics is proposed to be fundamental to evolution and the likelihood of acquiring many diseases. This article explores the hypothesis that, for transgenerationally inherited chromatin structures, "genotype predisposes epitype", and that epitype functions as a modifier of gene expression within the classical central dogma of molecular biology. Evidence for the causal contribution of genotype to inherited epitypes and epigenetic risk comes primarily from two different kinds of studies discussed herein. The first and direct method of research proceeds by the examination of the transgenerational inheritance of epitype and the penetrance of phenotype among genetically related individuals. The second approach identifies epitypes that are duplicated (as DNA sequences are duplicated) and evolutionarily conserved among repeated patterns in the DNA sequence. The body of this article summarizes particularly robust examples of these studies from humans, mice, Arabidopsis, and other organisms. The bulk of the data from both areas of research support the hypothesis that genotypes predispose the likelihood of displaying various epitypes, but for only a few classes of epitype. This analysis suggests that renewed efforts are needed in identifying polymorphic DNA sequences that determine variable nucleosome positioning and DNA methylation as the primary cause of inherited epigenome-induced pathologies. By contrast, there is very little evidence that DNA sequence directly determines the inherited positioning of numerous and diverse post-translational modifications of histone side chains within nucleosomes. We discuss the medical and scientific implications of these observations on future research and on the development of solutions to epigenetically induced disorders.
\end{abstract}

\section{Review}

\section{Cause-and-effect and epigenetic risk}

The inheritance of numerous genetic risk factors for human and plant diseases as well as biotic and abiotic stress susceptibility phenotypes are well established [16]. Particular DNA mutations and their mechanistic effect on the timing, level, or quality of gene expression produce the risk of disease. Thus, a clear cause-andeffect relationship is established between the inherited aberrant genotype and the risk phenotype (that is, the increased chance or certainty of presenting a disease).

\footnotetext{
* Correspondence: meagher@uga.edu

Genetics Department, Davison Life Sciences Building, University of Georgia, Athens, GA 30605, USA
}

\section{Biomed Central

Epigenetics is cited as contributing to the risk of acquiring numerous diseases and aberrant phenotypes in human and plant populations based primarily on correlations between changes in chromatin structure and penetrance of the undesired phenotype [7-10]. There has been a growing suspicion, particularly since the 1980s, that - along with classical genetics - epigenetics is required to explain many complex phenotypes associated with disease $[11,12]$. The influences of age and environment (for example, chemicals, heat, nutrition, daylight) on various pathologies and the seemingly stochastic penetrance of developmental abnormalities are particularly difficult to interpret using purely molecular genetic models and are more easily explained by considering epigenetic control mechanisms [13-18]. However, few cause-and-effect relationships have been established 
that prove that that particular inherited cis-linked chromatin structures (epitypes) are in fact useful in predicting the inherited risk of acquiring disease phenotypes. Exceptions are the epigenetic silencing of the skeletalmuscle ryanodine-receptor gene (RYR1) that causes congenital myopathies and the MutL Homolog 1 gene (MLH1) that causes increased risk of colorectal or endometrial tumors, which are discussed in the following section.

Inherited risk epitypes should evolve in populations in ways similar to the evolution of genotypes [19]. The problem is that the transgenerational inheritance of epigenetic controls is not well understood in any multicellular organism and often difficult to prove. This is particularly true in humans and agricultural crops, where the need for understanding epigenetic risk is the greatest [20-27]. Without knowledge about the molecular basis for the transgenerational inheritance or generational reprogramming of defined epigenetic risk factors that contribute to disease, it is difficult to design effective targeted therapeutics for humans or to knowledgably alter breeding programs for crops that will avoid the onset of a disease phenotype [28-32].

This study explores the cause-and-effect relationships among genotype, epitype and phenotype, where the epitype of a single gene or an entire genome is defined as its various cis-linked chromatin structures (Figure 1) [19]. Thus, epitype includes - but is not limited to chromatin domain structures, such as large DNA loops, the position of all nucleosomes and of subclasses of nucleosomes with particular histone variant compositions (for example, H2A or H2AZ or H2AX), DNA cytosine methylation, and a myriad of histone posttranslational modifications (PTMs) [33-35]. By focusing on epitype, we eliminate from consideration several other classes of epigenetic controls such as cell-to-cell communication by morphogens or the inheritance of cell surface patterning [36-40]. Addressing these other epigenetic controls would distract this discussion from a focus on the transgenerational inheritance of chromatin structures.

A working hypothesis that emerged from a preliminary examination of the inheritance and evolution of various epitypes [19] is that "genotype predisposes epitype" for most transgenerationally inherited chromatin structures. Only epitypes that are transgenerationally inherited at significant frequencies may contribute to the primary cause of inherited epigenetic risk. Within this hypothesis, epitype and the machinery that alters epitype are modifiers of the central dogma of molecular biology (DNA $\rightarrow$ RNA $\rightarrow$ Protein) influencing the activity of DNA and RNA, as shown in Figure 2A. In addition, we will discuss how particular DNA and RNA sequences strongly influence the penetrance of some epitypes and resulting phenotypes. By this view transgenerationally inherited epitypes are not acting at a higher level than or independent of DNA sequence in determining phenotype (for example, RNA and protein expression, disease phenotype).

It will be useful at this point to make the distinction between the transgenerational epigenetic inheritance among parents and offspring and the somatic inheritance between mother and daughter cells within developing tissues and organs [20,23,26,41-45]. The inheritance of epitypes between dividing somatic cells, such as the transmission of a histone PTM [46], is undoubtedly essential to tissue and organ development [47-49] and may be subject to various environmental influences that reveal a phenotype [50]; however, inheritance among somatic cells need not contribute causally to epigenetic inheritance across organismal generations. Again, we are interested herein in identifying epitypes that may be the primary cause of transgenerationally inherited epigenetic risk of acquiring a disease phenotype.

To test this hypothesis our discussion is focused on finding evidence for gene-specific epitypes that supports or rejects cause-and-effect relationships between genotype, epitype and phenotype. Some of the strongest evidence we found, for or against our hypothesis, is summarized in Table 1, and comes from two different research strategies. The first approach (A) examines the penetrance of transgenerationally inherited epitypes that are known to activate or silence the expression of disease related gene(s), which in turn correlate with onset of the aberrant "disease" phenotypes. This direct approach requires the measurement of the frequency of the transgenerational inheritance of causative epitype(s), the relevant gene expression pattern(s), and the aberrant phenotype(s) among related individuals in a population known to be at risk. This method is powerful, produces convincing data, and in several cases reveals the clear contribution of genotype to epitype. But transgenerational measurements are very expensive and time consuming, particularly in the early stages of establishing cause-and-effect relationships to human or agricultural diseases.

The second and less direct approach (B) searches out epitypes that are duplicated, as DNA sequences are duplicated, and examines multiple copies of DNA sequence and epitype that have been evolutionarily coconserved. This approach establishes an unambiguous, and in many cases a statistically significant, correlation of a particular epitype with highly reiterated DNA sequence motifs, and/or examines the conservation of an epitype among duplicated gene sequences. With this strategy, the evolutionary conservation of epitypes among conserved sequences is used as a filter to identify epitypes that were transgenerationally inherited $[19,51]$. 


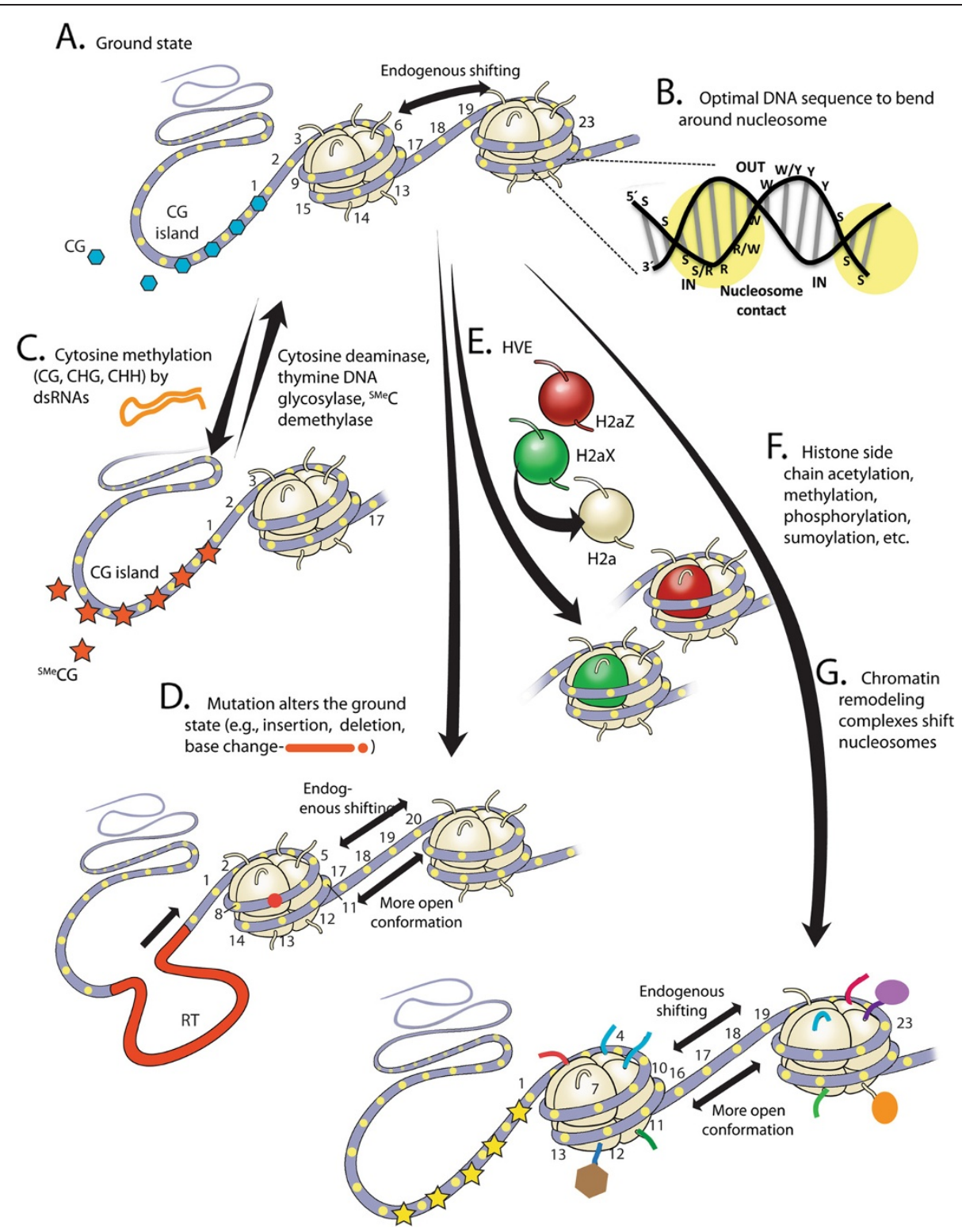

Figure 1 Summary of relationship between epitype and DNA sequence. A. Theoretical ground state for a chromatin structure comprised of naked DNA bound to two nucleosomes and an unbound upstream DNA region. Every 10 bp the approximately 2 bp of inward facing surface of the DNA helix has the potential to contact and bind nucleosomal histones (for example, yellow ovals numbered 1 to 23 for region surrounding one nucleosome, see $\mathbf{B}$ ). Each nucleosome has the potential to bind 14 such 2 bp regions. B. One 10 bp region of the DNA helix with the consensus ( $(Y) R R R R R Y Y Y Y Y(R)$ provides a bend for optimal nucleosome binding. Nucleotides that provide strong or weak nucleosome binding are indicated ( $\mathrm{S}=$ strong binding to $\mathrm{G}$ or $\mathrm{C}$ nucleotides, $\mathrm{W}=$ weak binding to $\mathrm{A}$ or $\mathrm{T}$ nucleotides, $\mathrm{R}=$ purine, $\mathrm{Y}=$ pyrimidine, IN identifies the surface facing the nucleosome, and OUT the surface facing away from the nucleosome). The strength of nucleosome binding and positioning to 147 bp stretches of DNA appears to be determined by the sum of affinities for 14 small sequences (yellow ovals, same as in $\mathbf{A}$ ). C. Double stranded (ds) RNAs (for example, siRNA, piRNA, miRNA) program cytosine methylation for transgenerational inheritance and somatic inheritance in different tissues, while various enzymes remove $5 \mathrm{MeC}$. D. Mutations such as single nucleotide polymorphisms (SNPs, red dot) and inserted retrotransposons (RT, red line) may alter nucleosome binding and the stochastic movement of nucleosomes. E. Histone variant exchange (HVE) by a subset of chromatin remodeling complexes (for example, SWR1) replaces common core histones (for example, H2A) with specialized protein sequence variants (for example, H2AZ, H2AX). F. A variety of histone post-translational modifications (PTMs) of primarily lysine and arginine residues at the $\mathrm{N}$ - and $\mathrm{C}$-termini of core histones produce a diverse "histone code" for different nucleosomes. G. A large number of chromatin remodeling machines (for example, SWI/SNF, INO80) control nucleosome positioning, often moving nucleosomes in approximately 10 bp increments. Not shown is that the individual epitypes interact with each other to produce complex epitypes. For example, a subset of individuals may contain in their genome a retrotransposons that is targeted by small RNAs, which cause the hypermethylation or hypomethylation of adjacent sequences and alters gene expression (that is, the interaction of $\mathbf{C}$ and $\mathbf{D}$ ). 


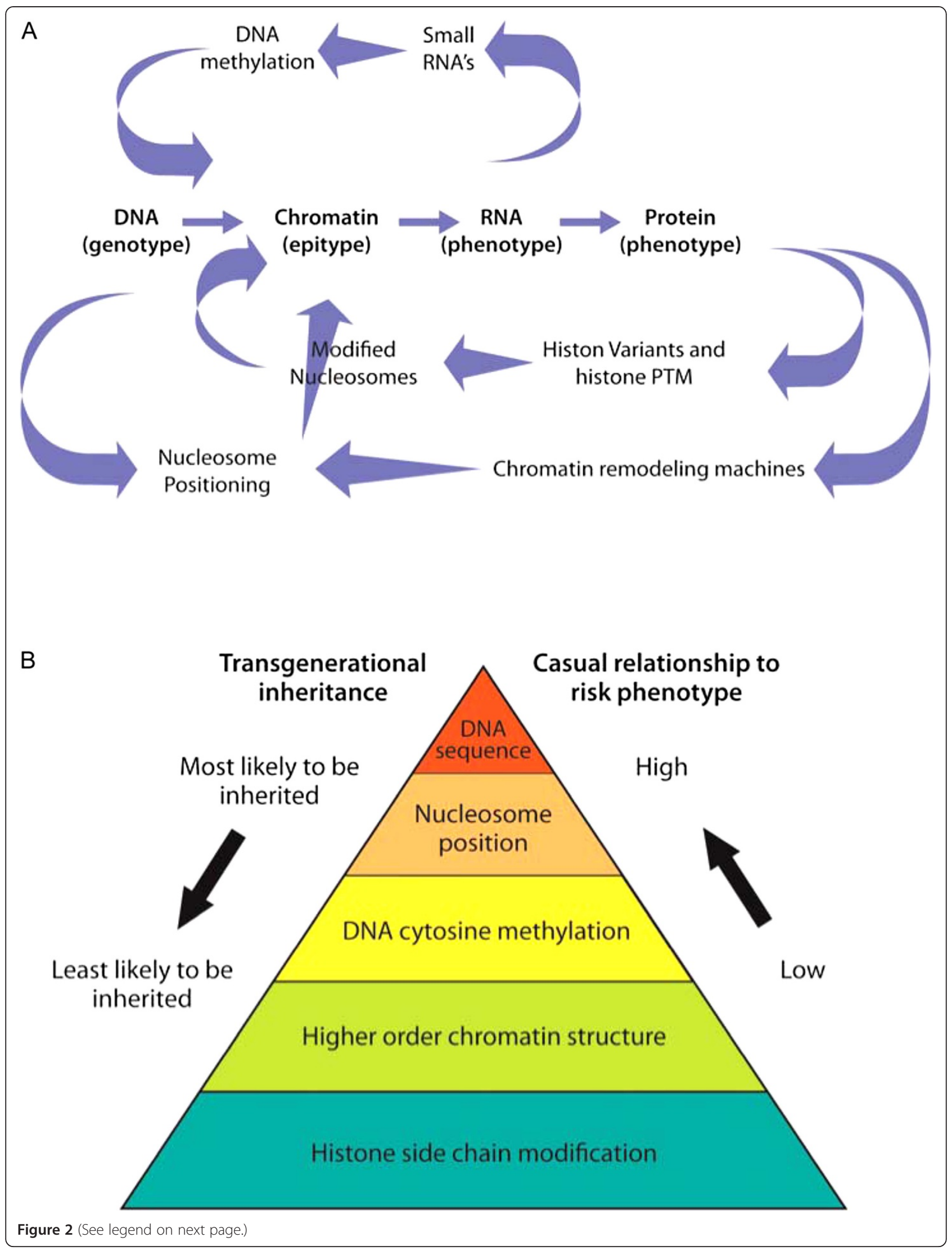


In other words, those epitypes that are widely conserved in their sequence position across the genome or may be shown to evolve by gene duplication within a gene family have almost certainly been inherited through past generations. Again, only epitypes that are transgenerationally inherited have the potential to contribute causally to inherited risk. This second approach simplifies analyses, because the initial screening for likely transgenerationally inherited epitypes may be made within a single genome and in one generation. Conversely, an epitype that is not inherited after gene duplication is less likely to be closely and causally related to phenotype, even if its presence in an allele correlates well with the disease phenotype. Hence, epitypes not inherited via DNA sequence duplications are likely to be poor predictors of inhereted epigenetic risk. The disadvantage of this second genome-centered approach is precisely that it is not focused on finding associated risk phenotypes and during the early stages of analysis we are frequently left with very large datasets describing relationships among epitypes and genotypes without yet knowing correlated pathologies.

\section{Direct measurement of transgenerational epigenetic inheritance}

Only a handful of studies have succeeded in fully demonstrating that the transgenerational transmission of an epitype produces changes in known target gene expression, which results in a disease or its risk of penetrance (that is, a causal relationship between genotype, epitype, and risk). Two of the best examples from humans concern chromatin structure at the RYR 1 and MLH1 genes, resulting in muscle myopathies and cancer, respectively. However, the complexity of the data on these two systems highlights the problems that arise when trying to establish such cause-and-effect epigenetic relationships, particularly in humans.

(1) RYR1: Genetic mutations causing a loss of expression of RYR1 function are associated with susceptibility to malignant hyperthermia and congenital myopathies (for example, central core disease, multiminicore disease) [52-54]. However, many individuals with core myopathy disease are known to be heterozygous for a mutant defective ryr1 allele [54,55]. The epigenetic silencing of the otherwise functional $R Y R 1$ allele appears to account for the loss of functional RYR1 protein expression. For example, among a sampling of 11 patients with the disease, six patients showed tissue-specific silencing of the maternally inherited functional RYR1 allele, which apparently resulted from cytosine hypermethylation of that allele [56]. Treating skeletal-muscle myoblasts cultured from these patients with 5-aza-deoxycytidine, an inhibitor of cytosine methylation in newly replicated DNA, reactivates the transcription of the epigenetically silenced, but otherwise functional allele. These data strongly support the view that hypermethylation is the primary cause of $R Y R 1$ silencing and onset of an epigenetically determined form of the disease (Figure 2). However, the particular region(s) of DNA in which cytosine residues are methylated to cause gene silencing has not been identified in spite of intense efforts to identify it among three CG islands within the gene. This leaves open the possibility that an epigenetically controlled transacting factor is the causative agent [56]. Thus, for RYR1 there is not yet a clear causal link between an aberrant genotype, epitype, and the silenced RYR1 gene expression producing the disease (Table 1 ).

(2) MLH1: The human $M L H 1$ gene encodes a homologue of the bacterial mismatch DNA repair protein MutL and, hence, $M L H 1$ is classified as a tumor suppressor. Hypermethylation of DNA cytosine residues and silencing of a particular functional MLH1 alleles (for example, -93 single nucleotide polymorphism (SNP)) [57], when paired with a dysfunctional mutant allele of the same gene, correlates with relatively young individuals developing tumors of the colorectum or endometrium $[27,58]$. The tumors and tumorderived cell lines from individuals with these hypermethylation epimutations fail to express MLH1 protein from this otherwise functional allele [59]. The hypermethylation of the potentially functional MLH1 allele and its transcriptional silencing is found in most organs and tissues of individuals who also have hypermethylation of this $M L H 1$ allele in their tumors. Hence, one might expect that this heritable epimutation resulted from the transgenerational inheritance of this epitype. However, studies of the children of these individuals generally show loss of hypermethylation and loss of 
Table 1 Examples of genes and specific sequences that support or reject the hypothesis that genotype predisposes transgenerationally inherited epitype and phenotype

\begin{tabular}{|c|c|c|c|c|c|}
\hline Genes/Sequences affected & Genotype contribution & Known aberrant epitype/gene expression & $\begin{array}{l}\text { Phenotype of epimutation or } \\
\text { epigenetic change }\end{array}$ & Species & $\begin{array}{l}\text { Supports/rejects } \\
\text { hypothesis }\end{array}$ \\
\hline \multicolumn{6}{|c|}{ A. Direct analysis of trans-generational inheritance } \\
\hline 1. RYR1 ryanodine-receptor & Unknown & Cytosine hypermethylation/silenced & hyperthermia, core myopathies & human & Rejects \\
\hline $\begin{array}{l}\text { 2. MLH1 (Homolog of mismatch } \\
\text { repair protein MutL) }\end{array}$ & Allele specific silencing & Cytosine hypermethylation/silenced & Colorectal or endometrial cancers & human & Weakly supports \\
\hline 3. AGOUTI (paracrine signaling peptide) & Alleles with retrotransposon & Cytosine hypomethylation/activation & Yellow, obese & mouse & Supports \\
\hline 4. AXIN1-FUSED & Alleles with retrotransposon & $\begin{array}{l}\text { Cytosine hypomethylation, histone } \\
\text { acetylation/activation }\end{array}$ & Axin-fused kinked tail & mouse & Supports \\
\hline 5. CNR Colorless Non-Ripening & Native $\mathrm{CpG}$ rich region & Cytosine hypermethylation/silenced & Carotenoid synthesis & tomato & Rejects \\
\hline 6. CYC - cycloidea (transcription factor) & $\begin{array}{l}\text { Native } C p G \text { rich region and } \\
\text { possible genotype difference }\end{array}$ & Cytosine hypermethylation/silenced & Floral morphology & Linaria vulgaris & Likely supports \\
\hline 7. H3K4Me2 demethylase & None identified & $\begin{array}{l}\text { Histone } \mathrm{H} 3 \text { lysine } 4 \text { dimethylation } \\
\text { retained causing gene activation }\end{array}$ & Germ line immortality & $\begin{array}{l}\text { Caenorhabditis } \\
\text { elegans }\end{array}$ & Likely rejects \\
\hline $\begin{array}{l}\text { 8. Quantitative epigenetic trait } \\
\text { loci (for example, many loci) }\end{array}$ & $\begin{array}{l}\text { DNA DEMETHYLATION1 ddm1/ } \\
\text { ddm1 restored to DDM1/DDM1 }\end{array}$ & Cytosine re-methylation and re-silencing & Flowering time and plant height & $\begin{array}{l}\text { Arabidopsis } \\
\text { thaliana }\end{array}$ & Supports \\
\hline $\begin{array}{l}\text { 9. Reprogramming of }{ }^{5 \mathrm{Me}} \mathrm{C} \\
\text { by dsRNA }\end{array}$ & $\begin{array}{l}\text { siRNA, miRNA, piRNA, and } \\
\text { other dsRNAs }\end{array}$ & Cytosine re-methylation and re-silencing & $\begin{array}{l}\text { Complex, molecular, and } \\
\text { developmental }\end{array}$ & $\begin{array}{l}\text { Arabidopsis, } \\
\text { mice }\end{array}$ & Supports \\
\hline 10. Somatic cell nuclear transfer & Genome-wide & $\begin{array}{l}\text { Cytosine re-methylation and histone } \\
\text { modifications }\end{array}$ & Embryonic and fetal development & $\begin{array}{l}\text { Mice, sheep, } \\
\text { pigs, cows }\end{array}$ & Mostly supports \\
\hline \multicolumn{6}{|c|}{ B. Indirect analysis using sequence conservation and gene duplication } \\
\hline $\begin{array}{l}\text { 1. RRRRRYYYYY repeat } \\
\text { throughout the genome }\end{array}$ & $\begin{array}{l}10.5 \text { bp repeats position most } \\
\text { nucleosomes }\end{array}$ & N.M. & N.M. & $\begin{array}{l}\text { Diverse animal } \\
\text { species }\end{array}$ & Supports \\
\hline $\begin{array}{l}\text { 2a. Histone } \mathrm{H} 2 \mathrm{AZ} \text { in }>1,000 \\
\text { nucleosomes }\end{array}$ & $\begin{array}{l}10 \text { bp repeat of } G+C \text { and } A+T \\
\text { rich dinucleotides }\end{array}$ & Histone H2AZ variant positioning & Potentiated for expression. N.M. & $\begin{array}{l}\text { Yeast, human, } \\
\text { Arabidopsis }\end{array}$ & Supports \\
\hline 2b. H2AZ in FLC, MAF4, MAF5 & $\begin{array}{l}\text { Subfamily of three recently } \\
\text { duplicated MADS box genes }\end{array}$ & $\begin{array}{l}\text { Bimodal distribution of } \mathrm{H} 2 \mathrm{AZ} \text { enriched } \\
\text { nucleosomes/activated }\end{array}$ & $\begin{array}{l}\text { Altered flowering time and } \\
\text { gene expression }\end{array}$ & Arabidopsis & Supports \\
\hline $\begin{array}{l}\text { 3. Histone CenH3 in 100,000 } \\
\text { nucleosomes }\end{array}$ & $\begin{array}{l}10 \text { bp repeat of } \mathrm{AA} \text { or } \Pi \mathrm{T} \\
\text { dinucleotides }\end{array}$ & Histone CenH3 variant positioning & $\begin{array}{l}\text { Essential for chromosomal } \\
\text { segregation. N.M. }\end{array}$ & maize & Supports \\
\hline 4. Blood plasminogen genes (PMGs) & $\begin{array}{l}\text { Cytosine methylation in } 208 \text { bp } \\
\text { region upstream of four PMG genes }\end{array}$ & N.M. & $\begin{array}{l}\text { Demethylation activates four } \\
\text { linked PMG alleles genes in liver. } \\
\text { Methylation silences in other organs. }\end{array}$ & human & Supports \\
\hline 5. 1600 segmental duplications & Duplicated gene sequences & $\begin{array}{l}\text { Several different histone side } \\
\text { chain modifications }\end{array}$ & $\begin{array}{l}\text { Duplicate alleles generally silenced } \\
\text { relative to active parental allele. N.M. }\end{array}$ & human & Rejects \\
\hline 6. HoxD cluster & $\begin{array}{l}\text { Five gene duplicated HOXD } \\
\text { genes }\end{array}$ & $\begin{array}{l}\text { Modestly conserved nucleosomal } \\
\text { and H3K4Me2 patterns }\end{array}$ & N.M. & human & Supports \\
\hline 7. DNA loops and microsatellites & $\begin{array}{l}\text { Concatenated DNA loops and } \\
\text { trans-chromosomal contacts }\end{array}$ & $\begin{array}{l}\text { Binding by HMG box proteins to } \\
\text { control gene expression }\end{array}$ & N.M. & mammals & Modestly supports \\
\hline
\end{tabular}


silencing of this $M L H 1$ allele in the first generation of transmission. Out of several individuals examined, only in one case was the epitype of hypermethylation and silencing inherited through the male parent to the individual with the disease. The MHL1 silencing phenotype in females with colorectal cancer was associated with a particular CG island centered at $-93 \mathrm{bp}$ from the start of transcription in a particular MHL1 allele containing a SNP, -93 SNP, in this region as illustrated for the more general case in Figure 1C,D [57]. While 5-aza2'-deoxycytidine will reactivate the silenced allele in cultured cancer cell lines, demethylation is also correlated with a shift in nucleosome position and increased nucleosome density in the promoter region Figure 1A,G [60]. In a very recent study, laser capture microdissection of the ovarian epithelium from ovarian tumors of cancer patients was used to analyze the cell type specific epitype and shows that the hypermethylation of MHL1 is an early somatic event in the malignant transformation of these cells [61]. Cogent to a theme of this article is the fact that the MHL1 epitypes of aberrant nucleosome position and cytosine methylation appear to be dependent upon the genotype of the epigenetically silenced MHL1 allele (Table 1). Epimutations of other tumor suppressor genes including $\mathrm{MSH} 2, \mathrm{MSH} 6, \mathrm{PMS} 2$, and $B R C A 1$ have also been associated with colorectal cancers, but the cause-and-effect relationships with disease are less clear then they are for MHL1 [62].

There are considerably more robust examples of the transgenerational epigenetic inheritance from model genetic organisms and wild plants, where it is easier to analyze aberrant epitypes and associated phenotypes through multiple generations. A few of the best cases with solid supporting evidence for a relationship between epitype and phenotype will be summarized.

(3) AGOUTI: In mice, the secreted AGOUTI peptide functions normally as a paracrine regulator of pigmentation. However, the dominant constitutive expression of the AGOUTI gene also targets changes in the hypothalamus and adipose tissues and this aberrant expression causes obesity. Hypomethylated, transcriptionally active dominant epialleles of the agouti gene may be maternally inherited through meiosis. Variation in the penetrance of different active epialleles generates a distribution of offspring from abnormal yellow (agouti) obese mice to darker mice with normal amounts of fat [63-65]. Several of the best characterized hypomethylated active and dominant alleles of agouti (Agoutiiapy, Agoutiy,
Agoutivy) that are associated with a high penetrance of the yellow coat color and obesity phenotypes have promoter-containing retrotransposons positioned just upstream of the natural Agouti promoter $[66,67]$. For the best studied alleles, these altered promoter structures are correlated with the hypomethylation of agouti and constitutive AGOUTI protein expression. However, a recent detailed examination of the DNA methylation profiles of active and silent alleles suggest that hypomethylation alone may not fully account for the complex ectopic expression of Agouti [18]. Nonetheless, the Agouti examples give reasonable support for the hypothesis (Table 1, Figure 1C,D) that genotype predisposes epitype and aberrant phenotype. It would not be surprising to find a shift in promoter nucleosome position resulting from the various retrotransposon insertions contributing to the causative epitype.

(4) AXIN1-FUSED: Axin1 is an inhibitor of Wnt (a hybrid of the names for Wingless and Integration1) signaling that regulates embryonic axis formation in deuterostome animals. In mice, Axin1 is the product of the mouse Fused locus. Some murine alleles of Axin1-fused $(A x i n 1 F u)$ show variable and stochastic expression levels, where high expression of a hypomethylated allele correlates with an abnormal kinked tail. Highly penetrant $A x i n 1 F u$ alleles contain an upstream retrotransposon or retrotransposonmediated DNA rearrangement that alters chromatin structure and contributes to dominant transcript expression $[68,69]$. An active, highly penetrant mutant allele may be inherited maternally or paternally for multiple generations. Both cytosine hypomethylation and histone acetylation patterns are reported to correlate with increased $A x i n 1 F u$ expression and risk of abnormal tail development [70-72]. The causal relationships between genotype, the DNA methylation epitype, gene expression, and the kinked tail phenotype are supported by the fact that methyl donor dietary supplementation of the mothers, a treatment known to increase DNA methylation, reduced $A x i n 1 F u$ expression and halved the incidence of kinked tails. Conversely, treatment of mice with the histone hyperacetylation agent Trichostatin A increased Axin1Fu expression and the frequency of a kinked tail phenotype [72]. This same recent study examining the chromatin from blastocyst stage heterozygous $A x i n 1 F u /+$ embryos shows that dimethylation of lysine- 4 on histone $\mathrm{H} 3$ (H3K4Me2) as well as acetylation of lysine-9 on histone H3 (H3K9Ac) correlate with penetrant alleles [72]. By contrast, there was no correlation of blastocyst stage cytosine methylation with penetrant 
alleles. However, both the drug treatments and studies of development after the blastocyst stage only prove the importance of somatic epigenetic inheritance during tail development. Again, it is reasonable to propose that the presence of retrotransposon-mediated changes in DNA sequence, which are present in all the aberrantly expressed Axin1Fu alleles, is the primary cause of the transgenerational inheritance of epigenetic risk. A shift in nucleosome position in penetrant alleles could affect downstream cytosine methylation and histone PTM, resulting in higher Axin1Fu gene expression and the kinked tail phenotype. By this view, genotype determines the nucleosomal epitype, which produces other aberrant hypomethylation and histone PTM epitypes, leading to increased gene expression and the novel kinked tail phenotype (Figure 1, Figure 2A, Table 1).

(5) CNR: The tomato colorless non-ripening gene $C N R$ encodes a homolog of the animal SQUAMOSA promoter binding protein (SPB box protein). CNR is essential to normal carotenoid biosynthesis and fruit ripening in the tomato and provides one of the best examples of a stable transgenerationally inherited epitype producing an abnormal phenotype. The natural epialleles of CNR in the tomato Lycopersicon esculentum contain 18 methylated cytosine residues ( $5 \mathrm{MeCG}$ or $5 \mathrm{MeCHG}$, where $\mathrm{H}$ is $\mathrm{C}, \mathrm{A}$, or $\mathrm{T}$ ) in a 286 bp contiguous region [73]. Hypermethylation of this region and silencing of the CNR gene leads to colorless tomatoes low in carotenoids (Figure 1C). Because the phenotype is relatively stable, these epialleles were originally mistaken as mutant alleles. The silenced $c n r$ epiallele and active wild type CNR gene do not have any encoded DNA sequence differences for thousands of base pairs within or flanking this hypermethylated region. Thus, while there is no mutational basis for the change in epitype, the CNR gene is potentiated for a stochastic DNA methylation event, because it contains such a large number of strategically positioned cytosine residues in its sequence. While this example supports a link between the $C N R$ gene sequence, epitype, and risk phenotype (Table 1), there does not appear to be a particular genotype that predisposes the cytosine hypermethylation epitype. The significant question becomes, once the aberrant epitype is established, how is this hypermethylation epitype stably inherited through the germ line?

(6) CYCLOIDEA: The perennial plant in which CYCLOIDEA was first identified, Linaria vulgaris (Toadflax, Butter and Eggs), normally produces yellow and orange asymmetric flowers composed of three petals of different morphologies. "Mutant" plants are found in wild populations with aberrant abnormally symmetrical "peloric" flowers that are comprised of five evenly arrayed petals of similar morphology. Plants with these aberrant flowers were first characterized by Carl Linnaeus 260 years ago and collected as herbarium specimens [74]. The peloric floral phenotype is produced by the hypermethylation and transcriptional silencing of the gene encoding a transcription factor CYCLOIDEA (CYC) [75]. Inheritance of the recessive peloric floral phenotype and silenced $c y c$ epialalele is relatively stable, follows Mendelian segregation and, hence, appeared upon initial investigation to be a normal mutant allele. However, gene silencing always maps to a DNA polymorphic cyc308G allele with a single nucleotide polymorphism in an unmethylated region 308 nt downstream of the stop codon and never to the more common wild type CYC308A allele. Peloric individuals are homozygous recessive for the cyc308G allele with both copies being hypermethylated and completely silenced for RNA expression. Thus, it is reasonable to conclude that genotype predisposes epitype, gene silencing, and the peloric phenotype (Table 1, Figure 1C,D).

(7) Histone H3K4Me2 demethylase erases epigenetic memory in each generation: A number of histone PTMs such as H3K4Me2 are acquired during transcription and are associated with active genes [76]. These epigenetic marks are removed at different stages in development by an H3K4Me2 demethylase, known as LSD1 in humans and SPR-5 in Caenorhabditis elegans (Figure 1F). Removal of the H3K4Me2 epitype prior to meiosis by SPR-5 in Caenorhabditis elegans is essential for maintaining an immortal germline [77,78]. Within two-dozen generations of worms acquiring the recessive null genotype these spr-5 mutants have a brood size several-fold lower than wild type, with $70 \%$ of the worms being fully sterile. Homologs of LSD1 (SPR5) are found throughout the four eukaryotic kingdoms and a number of these genes are known to be essential for normal organismal development [79-81]. The unmodified H3K4 epitype is essential and retention of the histone PTM causes aberrant development. However, there is as yet little evidence that this particular histone PTM epitype is normally preserved through meiosis or that genotype plays any role in determining the H3K4Me2 epitype at any particular locus (Table 1).

(8) Inheritance of quantitative epigenetic trait loci. Two separate genome-wide epigenetic studies demonstrate that multi-generational inheritance of complex traits such as flowering-time, plant height, biomass, and bacterial pathogen resistance behave as 
quantitative epigenetic trait loci in Arabidopsis thaliana $[22,82,83]$. These studies used two independently derived sets of recombinant inbred lines (RILs), where one of the founding parents was a recessive null for one of two known genes necessary for DNA cytosine methylation. For example, one study begins with a fourth generation plant homozygous defective $d d m 1 / d d m 1$ that is highly compromised in a number of phenotypic traits due to DNA hypomethylation. DECREASED DNA METHYLATION1 (DDM1) is a Swi2/Snf2-like DNA-dependent ATPase chromatin remodeler required for most DNA cytosine methylation. The $d d m 1 / d d m 1$ line was backcrossed to wild type, and this heterozygous F1 $d d m 1 / D D M 1$ was backcrossed to wild type again and screened to obtain hundreds of separate DDM1/DDM1 lines. These lines were selfed to establish hundreds of epiallelic recombinant inbred plant lines (epiRILs) [22]. For several generations, approximately $30 \%$ of the DDM1/ DDM1 epiRILs displayed aberrant morphological phenotypes affecting flowering time and plant height, among other phenotypes. They assayed 22 epiRILs for the methylation of 11 candidate genes that are normally cytosine hypermethylated, but are hypomethylated in $d d m 1$. Six alleles showed partial remethylation and five alleles were completely remethylated producing the identical complex epitype for this later gene set to wild type. Control genes that were previously unmethylated remained unmethylated.

In one particular example, Johannes and colleagues [22] followed the methylation sensitive FWA gene, for which the ectopic expression of the hypomethylated epiallele in $d d m 1$ parental plants produces strong late flowering phenotypes [84]. All of the 22 randomly selected epiRILs were now normally methylated at FWA and flowered at normal times. However, when they examined three extremely late flowering lines from among the population of hundreds of epiRILs (that is, plants that flowered after more than 48 days versus 33 days to flowering in wild type) these epiRILs were almost completely hypomethylated at FWA and expressed high levels of FWA transcripts, accounting for their phenotype. Hence, out of hundreds, only a few of the epiRILs escaped from the remethylation of $F W A$, when DDM1 was restored.

In summary, aberrant DNA methylation epitypes at many loci and the resulting changes in downstream molecular and developmental phenotypes appear to be transgenerationally inherited. Most genes regain wild type methylation patterns and phenotypes within a few generations and the restoration appears to be sequence specific. Hence, the genetic machinery necessary for the de novo remethylation of these completely unmethylated loci is encoded in the Arabidopsis genome and remethylation did not require hemi-methylated DNA templates to be newly inherited. These data suggest that genotype predisposes this global cytosine methylation epitype.

(9) Reprogramming of DNA cytosine methylation by double stranded dsRNAs. The 5'-methylation of DNA cytosine residues occurs in three sequence contexts: $5 \mathrm{MeCG}, 5 \mathrm{MeCHG}$ and $5 \mathrm{MeCHH}$ (Figure 1C). A number of DNA methyl-transferases (DMTs) are known to methylate DNA cytosine in the $5^{\prime}$ position. DMT1 efficiently propagates hemimethylated symmetrical CG sequences and, hence, the somatic inheritance of islands of $5 \mathrm{MeCG}$ hypermethylation that may lead to gene silencing is not hard to explain. However, DNA methylation of all types is predominantly erased (that is, 80 to $90 \%$ loss of methylation) in germ line cells in the embryos of both plants and animals [85-87]. Hence, the reprogramming of $\mathrm{CG}, \mathrm{CHG}$, and $\mathrm{CHH}$ methylation and a mechanism for transgenerational inheritance of these epitypes has been of intense interest in recent years $[88,89]$. To simplify the discussion of the gene-specific DNA cytosine remethylation and subsequent inheritance of methylation, Richards [90] introduced three working categories: obligate, facilitative, and pure DNA methylation.

Epialleles in heterochromatic DNA that display obligate DNA cytosine methylation always remain methylated due to the presence of large numbers of transposable elements in various orientations producing dsRNA that promote a strong RNA interference response and adjacent target gene remethylation [91]. Genes within or closely adjacent to the centromer are good examples of obligate epialleles. Axin1Fu and AgoutiAy are typical examples of facilitative epialleles, because the presence of an upstream change in DNA sequence facilitates a seemingly stochastic epigenetic variation in methylation and phenotype. Because the wild type loci for these alleles lack an altered promoter element there is seldom any variation in the cytosine methylation epitype at the wild type loci. Pure epialleles are defined as those showing variation in cytosine methylation without a known genotypic cause and appear to be examples of de novo DNA cytosine methylation. If pure epialleles are truly independent of genotype, then they stand as strong evidence against our hypothesis. The well studied hypermethylation and silencing of wild-type $C N R$ and $R Y R 1$ alleles fit the definition of pure epialelles. Schmitz and colleagues [92] examined the 
complete methylome of 100 Arabidopsis lines propagated for 30 generations by single seed descent from a single parent. They observed that CG $\leftrightarrow 5 \mathrm{MeGC}$ single methylation polymorphisms (SMPs) occurred at a 10,000 -fold increased frequency per generation over the DNA base mutation rate, which they also measured (Figure 1D). While CG SMPs occurred primarily within gene bodies, large numbers of CHG and CHH SMPs occurred in flanking regions. Thus, novel inherited SMPs are generated at high frequencies and, if this remethylation is independent of DNA sequence, then pure epialleles are common.

One relevant question for this discussion is the following: are ostensibly pure epialleles truly independent of genotype, or are they simply facilitative epialleles for which we have not yet identified the associated cis- or trans-acting genes making dsRNAs that program inherited CG, CHG and CHH methylation epitypes? There is recent evidence supporting the latter interpretation that we now summarize.

Despite being generated through slightly different mechanisms, many classes of small RNAs (for example, siRNA, miRNA, piRNA) are known to template the remethylation of cytosine in different sequence-specific contexts (Figure 1C) for the transgenerational inheritance of gene silencing and or activation [89,93]. This general mechanism for reprogramming using different classes of small RNAs appears ancient in that it is found in all four eukaryotic kingdoms. These RNAs facilitate the remethylation of appropriate CG, GHG, and $\mathrm{CHH}$ sequences. But these data began to raise the question: does remethylation occur on a global genome-wide scale? To address the scope of remethylation, Teixeira and colleagues [94] examined the remethylation of numerous transposable element loci in DDM1/DDM1 epiRIL plants that had descended from an essentially unmethylated $d d m 1 / d d m 1$ plant backcrossed to wild type. Those loci that were remethylated after a few generations in the epiRILs contained cytosine rich gene sequences that were highly complementary to the sequence of siRNAs. Those loci with similar cytosine rich composition for which they could not identify complementary siRNAs remained hypomethylated. siRNAs attract RNA interference (RNAi) and DNA methylation machinery to complementary DNA sequences and thereby template sequence-related DNA methylation [95]. This shows that RNAi mechanisms are essential for the proper remethylation of much of the Arabidopsis genome. These and other data make it clear that, for a large number of repetitive elements in yeast, plants, and animals, the matching genotypes of structural genes and small RNAs predict a cytosine methylation phenotype. However, the study of Teixeira and colleagues [94] raises further questions about the biology, regulation, and timing of cytosine remethylation for both transgenerational and somatically inherited epitypes. Recent evidence suggests that in both plants and animals "nurse cells" may transfer hundreds of undefined small RNAs to adjacent egg or sperm germ cells to reprogram cytosine methylation $[88,89,93]$. For example, in mice in which $80 \%$ to $90 \%$ of the germline DNA methylation is erased for single copy genes at approximately day 11.5 of embryo development (E11.5). Remethylation of sperm DNA occurs in the embryo at approximately E16.5 and is significantly directed by populations of 24 to $30 \mathrm{nt}$ long piRNAs produced in adjacent cells in the prospermatogonia [96-98]. The identities of most of the plant and animal small RNAs transferred to developing germ cells are not yet known, but there is the real potential that large populations of RNAs may account for most transgenerational remethylation and perhaps even the apparent de novo methylation described by Schmitz and colleagues [92]. Appropriately positioned target sequences in these epialleles and thousands of expressed small RNAs would have to be inherited together for genotype to predispose the transgenerational inheritance of the global DNA methylation epitype.

(10) Reprogramming epitype during somatic cell nuclear transfer. In most of the above examples, genotype determines the likelihood, but not the certainty, of particular epitypes and phenotypes being displayed, because the same DNA sequence may be flexibly reprogrammed into many different chromatin conformations. It is fundamental to epigenetics that as cell types differentiate the same DNA sequence may display multiple epitypes and some epitypes may be more or less stable than others. An interesting example of a variety of epitypes descending from one genotype comes from research using somatic cell nuclear transfer (SCNT) to produce identical or genetically modified laboratory and farm animals. SCNT is achieved by transplanting a somatic cell nucleus into a functional embryonic cell capable of forming a viable organism. This technology has met with modest success, generating cloned mice, rabbits, pigs, sheep, cows and more, but the efficiency of obtaining viable healthy offspring is low. Even if genetically modified embryos are established in surrogate mothers, developmental abnormalities and spontaneous abortions are common. A major limitation to obtaining relatively normal full-term development appears to be variations in epigenetic reprogramming of the transplanted nucleus [99102]. The field of regenerative medicine faces similar problems with epigenetic reprogramming when trying to establish genetically altered lines of 
induced pluripotent stem cells by SCNT - for example, by transferring a somatic cell nucleus into an oocyte $[103,104]$. Without prior knowledge of the successes in producing cloned animals by SCNT, one would not necessarily expect that the new nuclear environment should correctly reprogram the donated nucleus. A known source of the reprogramming problem in the animal cloning field is that the transferred nucleus frequently loses a significant fraction of its DNA cytosine methylation and nucleosomal histone side chain methylation and acetylation relative to the more modified epitype of nuclei in native embryonic cells (Figure 1C,F) [105-109]. However, the surprising fact remains that some relatively healthy animals resembling the nuclear donor are obtained via SCNT and that genetic and epigenetic totipotency of the donor nucleus is re-established in the viable offspring. For appropriate reprogramming to take place on a genome-wide scale the donor DNA sequence must have the capacity to interact with the embryonic cellular environment and determine, albeit at low frequency, an epitype(s) compatible with full-term development. These results support the idea that during SCNT the donated DNA sequence predisposes much of its own epigenetic reprogramming (Table 1).

\section{Evolutionary co-conservation of DNA sequence and chromatin structure filters out transgenerationally inherited epitypes}

If genotype pedisposes epitype then a reasonable corollary is that some transgenerationally inherited chromatin structures should align with particular DNA sequence motifs and be passed on to duplicate gene copies. In this model, the range of possible epitypes for a sequence would evolve by gene duplication and mutation in parallel with genotype [19,51]. Rapidly evolving epitypes might only be conserved and identifiable among very recently duplicated genes examined among a limited number of related cell types or when examined statistically in comparisons of large numbers of aligned sequences, while slowly evolving highly conserved epitypes might be found among anciently duplicated genes and descended from a common ancestral protist sequence.

(1) Short DNA sequence repeats such as RRRRRYYYYY determine the bending and positioning of DNA around the nucleosome. More than 30 years ago, Trifonov and his colleagues $[110,111]$ presented the case that gene sequence is fundamentally important to nucleosome positioning. He argued that the necessary high degree of bending of DNA as it wraps twice around and binds the nucleosome would be favored by particular 10.5 bp repeat sequences of approximately 5 purines $(\mathrm{R})$ followed by 5 pyrimidines (Y) (RRRRRYYYYY) (Figure 1B), or the inverse of this sequence, $Y Y Y Y Y R R R R R$. He also found a good correlation for $10 \mathrm{bp}$ repetitions of the dinucleotides GG, TA, TG, and TT in the modest compilation of 30,000 bp of DNA sequence from different eukaryotes available at that time. ${ }^{\mathrm{a}}$ Within the $10 \mathrm{bp}$ motif these dinucleotides were proposed to help position nucleosomes. The statistical concept was a bit counterintuitive and slow to gain acceptance, because it was hard to reconcile the functional demands of sequences encoding proteins and regulatory regions with the proposed special sequence demands of nucleosome interaction. Recently, with access to nearly unlimited numbers of nucleosome-delimited 147 bp DNA sequence fragments and more advanced computational methods, it has become very clear that 14 repetitions of the 10.5 bp repeat sequences $Y$ $R R R R R Y Y Y Y Y-R$ or $R-Y Y Y Y Y R R R R R-Y$ are statistically favored for nucleosome positioning. Regional differences in GC compositions in the genome favor particularly skewed repeats such as T-AAAAATTTTT-A or C-GGGGGCCCCC-G $[112,113]$. These consensus sequences are based on a statistical argument, and at the genome level any one dinucleotide such as $A A$ or $G G$ is seldom found in a particular position in the 147 bp repeat more than $30 \%$ of the time [114]. Because the inward facing helix of any one 147 bp of nucleosomal DNA fragment has 14 chances to contact the core of nucleosomal proteins, this mechanism requires only several correctly positioned dinucleotides contacting the nucleosome to give sequence specificity to nucleosome positioning. Hence, there is in fact little conflict with conserved coding and regulatory sequences and the sequence constraints of nucleosome positioning. Furthermore, the most common classes of ATP-dependent chromatin remodeling machines, switch/sucrose nonfermentable (SWI/SNF) and imitation switch (ISW)2, move DNA in approximately 9 to $11 \mathrm{bp}$ increments over the surface of a nucleosome, consistent with the importance of 10.5 bp repeats in nucleosome binding [115]. These data strongly support a model where genotype predisposes possible nucleosome position epitypes. More particular support for this argument comes from examining the sequences for subsets of the 
nucleosomal DNA population binding nucleosomes containing histone variants $\mathrm{H} 2 \mathrm{AZ}$ and CENH3.

(2a) The geneome-wide positioning of $H 2 A Z$ nucleosomes. The histone variant H2AZ and likely other histone variants are inserted into assembled nucleosomes by histone variant exchange complexes (HVE) such as SWR1 (Figure 1E). Albert and colleagues [116] precisely aligned the sequences of thousands of $147 \mathrm{bp}$ yeast nucleosomal DNA fragments enriched for histone variant H2AZ. Their data show conclusively that $\mathrm{H} 2 \mathrm{AZ}$ nucleosome positioning on a genome-wide scale is strongly influenced by dinucleotide repeat patterns spaced 10 bp apart in the DNA sequence (Figure 1A,B). In particular, GC-rich dinucleotides are on the inside as the DNA helix wraps around the nucleosomal protein core, and AT-rich dinucleotides are on the outside. The preference for these nucleotide pairs at each of their 14 possible positions within any $147 \mathrm{bp}$ nucleosomal fragment is only about 2 to $9 \%$, and therefore any single nucleosomal fragment sequence is likely to vary significantly from the statistical consensus. However, it is clear that the H2AZ nucleosome position is determined by the overall pattern in the DNA sequence and, hence, H2AZ nucleosome position will be conserved following gene duplication.

Similar results were obtained for genome-wide positioning of all nucleosomes from humans and Arabidopsis [117] and subsets of human nucleosomes specific to certain classes of genes [118]. In the total $147 \mathrm{bp}$ nucleosomal fraction from Arabidopsis and humans, an AT-rich dinucleotide repeat is spaced every $10 \mathrm{bp}$ and out of phase by 5 bp with a GC-rich dinucleotide repeat.

(2b) Further support for the concept that DNA sequence positions H2AZ nucleosomes comes from a comparison of duplicated genes in Arabidopsis. A single peak of H2AZ enriched nucleosome(s) is found at the $5^{\prime}$ end of nearly half of all plant, animal, and fungal genes that have been examined [116,119-121]. In Arabidopsis, three related MADS box genes that regulate flowering time require normal H2AZ for full expression. In wild-type cells, all three MADS box genes show a striking bimodal distribution of H2AZ deposition, with peaks of H2AZ histone-containing nucleosomes at their $5^{\prime}$ and $3^{\prime}$ ends [122]. This pattern is quite distinct from the single $5^{\prime}$ spike of $\mathrm{H} 2 \mathrm{AZ}$ observed for other MADS genes in humans, Arabidopsis, and yeast. These three genes are estimated to have diverged from a common gene ancestry in the eudicot plant lineage in the last 100 million years and stand alone in their own distinct clade, among more than 100 other MADS box genes in Arabidopsis that do not have a bimodal distribution of H2AZ nucleosomes. These data are consistent with the bimodal distribution of H2AZ being inherited following gene sequence duplication from an ancestral MADS gene [19].

(3) The genome-wide positioning of CENH3 centromeric nucleosomes. Recent experimental evidence demonstrates that CENH3 enriched centromeric nucleosome positions are determined by DNA sequence. Animal and plant centromeres are composed of a diverse variety of retroelements and repetitive satellites that generally appear unrelated in their DNA sequences. Numerous earlier studies of centromere and neocentromere sequences concluded that a distinct conserved DNA sequence was not essential to centromere activity. However, a very recent analysis of 100,000 centromeric histone CENH3 enriched nucleosomal DNA fragments from maize suggests that a $10 \mathrm{bp}$ repeat of AA or TT dinucleotides contributes to determining the positioning of centromeric nucleosomes [123]. The CENH3 nucleosome specific sequence was not revealed until the $147 \mathrm{bp}$ micrococcal nuclease protected DNA sequences were precisely aligned. The preference for AA or TT nucleotide pairs at each of the 14 positions within a typical 147 bp nucleosomal fragment was statistically significant. The likelihood of finding one of these dinucleotide pairs at any of the potential contact points ranges from $13 \%$ to $60 \%$ above the frequency at which other dinucleotides are found. Thus, CENH3 enriched nucleosomes are positioned by a variation on what is shown in Figure 1B, where the inward facing DNA base pairs that bind are generally AA or TT and would be classified as weak binding. This would indicate that any single centromeric nucleosomal sequence may vary significantly from the statistical consensus for these nucleotide pairs. In this way, a subset of retroelements that are seemingly unrelated in sequence using standard sequence alignment methods may contain suitable sequence repeats that position centromeric nucleosomes.

The human and Arabidopsis genomes each encode more than a dozen histone protein sequence variants for each of three classes of histones, H2A, $\mathrm{H} 2 \mathrm{~B}$, and H3. Within each class a few subclass variants are easily identified as predating the divergence of plants, animals, and fungi from their more recent protist ancestors. Thus, it is reasonable 
to speculate that distinct DNA sequence patterns evolved in concert with each histone variant subclass to provide complex patterns of nucleosome positioning. If true, then DNA sequence would be responsible for the transgenerational positioning of most classes of nucleosomes.

(4) Cytosine methylation in the human plasminogen gene family. In an attempt to show that epitypes and associated phenotypes can evolve by gene duplication and divergence, Cortese and colleagues [51] compared promoter CG methylation patterns among the four duplicated gene members of the approximately 35-million-year-old human plasminogen (PLG) precursor gene family, encoding blood-clotting factors found only in hominids. Cytosine DNA methylation patterns are well conserved among seven CG sites located -171 to -378 nucleotides upstream from the start of transcription within all four PLG gene promoters (similar to Figure $1 \mathrm{~A}, \mathrm{C}$ ). In liver, where transcripts for all four genes are expressed, one allelic copy of each gene pair is almost completely unmethylated at all seven sites. In heart muscle and in skeletal muscle, where the four PLG genes are turned off, nearly $100 \%$ of the seven sites are fully cytosine methylated on both alleles for all four genes. In other words, promoter cytosine methylation silences all gene copies in the two nonexpressing tissues examined, while hypomethylation of one copy of each PLG gene activates their expression in liver. The $P L G$ data support the generational inheritance and conservation of the cytosine methylation epitype following gene duplication for recently duplicated genes that are co-expressed. Cortese and colleagues [51] also compared promoter CG methylation patterns among several members of the much older human T Box (TBX) gene family in which the most gene duplications date back 300 to 600 million years. No evidence was obtained for conserved CG methylation patterns among any pair-wise comparison of $T B X$ genes. Perhaps because the TBX genes are differentially expressed and the divergence events between genes are much more ancient, the lack of conserved CG methylation patterns is to be expected.

(5) Histone side chain modifications in human segmental sequence duplications. Barski and colleagues [124] published a ground-breaking genome-wide study on sequence specific location of 23 histone PTMs and a few other epitypes in purified human CD4+ T cells. From this dataset, Zheng [125] examined 14 distinct patterns of histone PTM in nucleosomes from 1,646 relatively recent (that is, less than approximately 25 millionyear-old) segmental chromosome duplications (SDs). They found no significant evidence for the inheritance of these histone modifications between the original and derived loci. Specifically, the duplicated copy did not inherit the parental pattern of histone side chain methylation or acetylation (Figure 1F). Moreover, inheritance appears to be distinctly asymmetric for some of the modifications, such that there is a strong statistical bias toward histone methylation of one gene copy for each SD and not the other copy, beyond what might have occurred at random. Many of the asymmetrical histone modifications correlate with gene activation and repression, suggesting that active genes in the parent sequence are silenced in the duplicated loci, and visa versa. These data imply that histone PTM epitypes may not be the direct transgenerationally inherited "cause" of the phenotypes with which they are associated. Thus, these data on histone PTM epitypes at SDs do not support our working hypothesis. If these results are supported by more experimental studies, it will not mean that histone modifications are not useful epitypes for predicting risk, but that they may be further from the inherited cause of epigenomeinduced pathologies than other epitypes such as nucleosome position and cytosine methylation. Histone PTMs are indeed important to somatic inheritance and development $[46,126]$.

(6) Nucleosome positioning and H3K4Me2 modifications in the HOXD cluster. There are six genes at the HOXD gene cluster (that is, HOXD13, $11,9,8,4,3)$ covering approximately 100,000 bp on human Chromosome 2. In human sperm, there are one or two spikes of general nucleosome occupancy and H3K4Me2-enriched nucleosome occupancy within each of the promoters of these genes, whereas the approximate $100,000 \mathrm{bp}$ of $5^{\prime}$ flanking region is relatively free of nucleosomes [127] (Figure 1A,F). Because nucleosome positioning was performed using microarrays, the sequence specificity of H3K4Me2-enriched nucleosomes among these HOXD promoters cannot be determined from these data or compared to the results from Barski and colleagues [124] who did not find sequence specificity for histone H3K4Me2-enriched nucleosome binding. These results showing the conserved positioning of nucleosomes in $H O X D$ promoters in human sperm are similar to those for H2AZ-enriched nucleosomes among the FLC-related MADS genes in Arabidopsis shoot tissue [122]. 
(7) Higher-order chromatin structures. Genes and regulatory sequences that are narrowly or widely spaced on a chromosome may interact productively through higher order chromatin structures such as solenoids, small and giant loops, and minibands [128130]. For example, small concatenated DNA loops may be formed by re-association of the single strands of the poly (CA)-poly (TG) microsatellite at their base [131]. These small loops appear to impact the control of gene expression via binding to HMG-box proteins $[131,132]$. There is mounting evidence that interactions of distant intra- and inter-chromosomal domains provide epigenetic mechanisms to maintain specialized gene expression states [133-135]. Hence, the potential exists that higher order structures contribute to epigenetic control and are determined in part by DNA sequence.

\section{Summary from direct and indirect analyses of epigenetic inheritance}

An examination of several examples of the direct transgenerational inheritance of epitype and the epitypes of duplicated and/or conserved DNA sequences revealed the complexities of determining cause-and-effect relationships among genotype, epitype and phenotype. However, in balance, there are robust experimental data supporting the hypothesis that "genotype predisposes epitype," for some epitypes (Table 1). In particular, it is becoming clear that a large fraction of, if not all, cytosine methylation is determined by gene sequence and the presence of paired sequence-specific complementary small RNAs that direct their transgenerational remethylation. Similarly, based on the sequences of $\mathrm{H} 2 \mathrm{AZ}$ and CENH3 enriched nucleosomal fragments, nucleosome position appears strongly influenced by DNA sequence (Figure 1A,B,C). However, there is little evidence suggesting that DNA sequence determines the position of any of more than 20 different classes of histone PTM enriched nucleosomes (Figure 1F, Table 1).

Based on this analysis, it is worth ranking the utility of various classes of epitype in estimating epigenetic risk. A risk pyramid linking the relationships of genotype and epitype with epigenetic risk phenotype is shown in Figure 2B. DNA sequence is placed at the apex, as the primary cause of inhereted epigenetic risk. This is followed by nucleosome position that appears to be directly dependent upon 10 bp repeats in DNA sequence and DNA cytosine methylation that is highly dependent upon cis-acting CG, $\mathrm{CHG}$, and $\mathrm{CHH}$ sequences in the target gene and the sequence of trans-acting small RNAs. However, while histone PTM may be strongly correlated with epigenetically controlled phenotype, there is no evidence that any histone PTM is causal to transgenerationally inherited risk. Histone PTM epitypes may represent the effect of other epigenetic and genetic controls and may be principally important to somatic inheritance of epigenetic controls. The clear relationship between novel genotypes and many of the most robustly characterized inherited epitypes of nucleosome position and cytosine methylation is a recurrent theme in the literature of the most thoroughly studied genes under epigenetic control. This suggests that human and animal therapeutic treatments or plant and animal genetic breeding strategies that address harmful meiotically inherited epitypes should consider the possibility that there are genotypic causes predisposing these epitypes. If, for example, the environment of a developing somatic tissue (for example, obesity, stress, nutrients) is influencing RNA sequence directed cytosine remethylation and gene silencing, drugs targeting downstream histone PTM epitypes of that gene may be less effective than ones addressing remethylation. Strategies directed at controlling gene expression by altering histone PTM epitypes may be useful if they target the gene or genes producing the disease's phenotype. Finally, the undeniable influence of genotype on epigenetic controls leading to deleterious phenotypes has to be taken into account in a consideration of epigenetic risk, even if it confounds many current, working definitions of epigenetics.

\section{Defining epigenetics}

We've summarized direct and indirect evidence that genotype predisposes epitype and that epigenetic controls are strongly influenced by DNA and RNA sequences (Figures 1 and 2). Our hypothesis and these supporting data may be viewed as contrary to some of the widely stated precepts of epigenetics. For example, Riggs and colleagues defined epigenetics as "the study of mitotically and/or meiotically heritable changes in gene function that cannot be explained by changes in DNA sequence" [34,136]. A rephrasing of this statement as "the study of mitotically and/or meiotically inherited changes in gene function that cannot be explained by the classical central dogma of molecular genetics" (Figure 2A) provides a working definition that is quite consistent with our deliberations. In David Nanney's seminal article describing epigenetic control systems, he states "The term "epigenetic" is chosen to emphasize the reliance of these systems on the genetic systems" and goes on to say "epigenetic systems regulate the expression of the genetically determined potentialities" [39]. Nanney's definitions of epigenetics are completely consistent with genotype predisposing inherited epitype, and with epitype modifying gene expression and risk phenotype.

\section{The influence of DNA sequence on epigenome-induced pathologies points a way forward}

Understanding that genotype predetermines many inherited epitypes suggests a few useful strategies and concerns 
as we try to address epigenome-induced pathologies. First, we are in a better technical position than ever before to determine the influence of genotype on epitype. New rapid DNA sequencing and DNA bead array methods for identifying SNPs and $5 \mathrm{MeC}$ residues combined with a wide selection of treatments to chromatin (for example, ChIP, bisulfite, micrococcal nuclease) allow us to quantitatively determine the precise genome-wide sequencespecific positioning of every nucleosome, methylated cytosine residue, and dozens of distinct histone PTMs in a genome. These epitypes may be correlated with the risk of cancer, behavioral disorders, pathogen susceptibility, or the role of aging and environmental factors on risk, as examples. The lower costs of genome-wide approaches is enabling the epitypes of larger populations of humans, laboratory animals, and plants to be examined in order to identify the epigenetic causes of complex diseases such as obesity, lupus, or pathogen susceptibility [137-140]. Second, we are in a position to develop batteries of gene-specific epigenetic biomarkers for DNA methylation epitypes that are clearly associated with disease risk and may be predictive of the penetrance of pathology. For example, this is currently being done for systemic lupus erythematosus, myeloid leukemia, and breast cancer [138,141-143]. However, new technologies are needed if we are also to use nucleosome position and histone PTM epitypes as inexpensive epigenetic biomarkers for screening populations. Third, because the development of each plant and animal cell type in an organ system is under strong epigenetic control, it is essential that we examine epitypes in distinct cell types within organs. Most current epigenetic studies examine mixed cell types such as are present in whole organs and tissues (for example, blood, tumor, hypocampus, skeletal muscle, plant shoots or roots), wherein cell type-specific epitypes are blurred due to variation of epitypes among developmentally distinct cell types. For example, several orders of magnitude more statistically significant relationships were obtained between the cytosine methylation epitype of various genes with lupus when CD4+ T cells were examined as compared to the data obtained from mixed populations of white blood cells [138,144]. Technologies have been developed to access cell type-specific epitypes, including laser cell capture micro-dissection, fluorescent activated cell sorting (FACS) of dissociated fluorescently tagged cells, and the isolation of nuclei tagged in specific cell types (INTACT). These technologies enable the more precise determination of epitypes within individual cell types as has been shown for CD4+ T cells, primordial germ cells, ovarian epithelium, retinal cones, and plant root epithelial trichoblasts and atrichoblasts [61,124,145148]. Fourth, therapeutic approaches to human epimutations that increase the risk of pathology, or plant breeding strategies to address epigenetic susceptibility to stress or disease, need to consider that molecular mechanisms may be obscurely hidden in DNA sequence motifs and/or the sequences of small RNAs that are imperfectly matched with their target genes (Figure 1). Current basic research is laying the course for using small RNAs to direct transcriptional gene silencing by promoter DNA methylation for therapeutics and crop improvement. For example, siRNA transgenes have been used for the methylationbased transcriptional silencing of the Heparanase gene in human cancer cells in culture [149] and to elucidate the mechanisms of small RNA-based transcriptional silencing in plants $[150,151]$. Unless we can develop therapeutic approaches, identifying genotypic influences on epigenetic risk may only add more diseases to the list of thousands for which we know the cause, but have no known cure. However, taking the numerous advances in epigenetics research altogether, it is reasonable to propose that during the next two decades effective therapeutic treatments will follow the dissection of the molecular mechanisms by which genotype and epitype interact to produce disease pathologies.

\section{Conclusion}

There is substantial evidence that altered epigenetic controls contribute to a variety of diseases ranging from cancer and developmental malformations to susceptibility to various forms of biotic and abiotic stress. We reviewed experimental genetic, epigenetic, cell biological, and biochemical data surrounding the transgenerational inheritance of several examples of well studied epigenomeinduced pathologies and the contribution of conserved DNA sequence motifs to epitype. The preponderance of evidence suggests that genotypes predispose epitypes for most chromatin structures that are transgenerationally inherited and this relationship contributes to the penetrance of epigenetically controlled diseases. Genotypes influencing inherited epigenetic risk are often obscurely encoded in DNA sequence and small RNAs. Furthermore, the remethylation of DNA cytosine residues may only be reprogrammed at particular times in development and only in particular tissues such that a special effort may be required to identify and characterize these mechanisms. Some of the best characterized examples that were discussed herein suggest we are only just beginning to understand the molecular biology behind inherited epigenome-induced disorders. Finally, the paths to effective therapeutic development or to lowering epigenetic risk will be easier to trace out once we understand the mechanisms by which genotype predisposes epitype for a particular disease.

\section{Endnote}

${ }^{\text {a}}$ Trifinov did not have nucleosome specific DNA sequence data available 30 years ago. 


\section{Abbreviations}

CNR: Colorless non-ripening; CENH3: Centromeric histone H3; CYC: CYCLOIDEA; DDM1: DECREASED DNA METHYLATION1; DMT: DNA methyltransferase; dsRNA: Double stranded RNA; epiRIL: Epiallelic recombinant inbred plant line; FACS: Fluorescent activated cell sorting; FWA: FLOWERING WAGENINGEN; H3K4Me2: Histone $\mathrm{H} 3$ dimethylated at lysine4; H3K9Ac: Histone H3 acethylated at lysine-9; HVE: Histone variant exchange complexes; INTACT: Isolation of nuclei tagged in specific cell types; ISW: Imitation switch; MLH1: MutL Homolog 1 gene; piRNA: Piwi-interacting RNA; PLG: Plasminogen; PTM: Post-translational modification; R: Purine; RIL: Recombinant inbred line; RNAi: RNA interference; RYR1: Skeletal-muscle ryanodine-receptor gene; SCNT: Somatic cell nuclear transfer; SD: Segmental chromosome duplication; siRNA: Small inhibitory RNA; SMP: Single methylation polymorphism; SNP: Single nucleotide polymorphism; SPB box protein: SQUAMOSA promoter binding protein; SWI/SNF: Switch/sucrose nonfermentable; TBX: T Box; Wnt: Is a hybrid of the names for Wingless and Integration 1; Y: Pyrimidine.

\section{Competing interests}

The authors declare that they have no competing interests.

\section{Authors' contributions}

RBM proposed the hypothesis that drove the content of the manuscript and wrote most of the manuscript. KJM helped with the conception of the manuscript and topics, designed the epigenetic risk pyramid, and contributed to the writing and fact checking. Both authors read and approved the final manuscript.

\section{Acknowledgements}

Drs Roger Deal, Muthugapatti Kandasamy, Jonathan Arnold, and Mary Anne Della-Fera offered useful editorial comments on the manuscript for which we are grateful. Kip Carter and the UGA's College of Veterinary Medicine's Department of Medical Illustration generously provided the artwork. This study was supported by a grant from the National Institutes of Health (GM36397-25) and the University of Georgia's Research Foundation to RBM and the UGA Graduate Student Association Recruitment Award, the Linton and June Bishop Graduate Fellowship, and the NIH Genetics Training Grant (GM 07103-37) awards to KJM.

Received: 2 May 2012 Accepted: 20 July 2012

Published: 20 July 2012

\section{References}

1. Fumagalli M, Cagliani R, Riva S, Pozzoli U, Biasin M, Piacentini L, Comi GP, Bresolin N, Clerici M, Sironi M: Population genetics of IFIH1: ancient population structure, local selection, and implications for susceptibility to type 1 diabetes. Mol Biol Evol 2010, 27:2555-2566.

2. Zhang B, Fackenthal JD, Niu Q, Huo D, Sveen WE, DeMarco T, Adebamowo CA, Ogundiran T, Olopade Ol: Evidence for an ancient BRCA1 mutation in breast cancer patients of Yoruban ancestry. Fam Cancer 2009, 8:15-22.

3. Hayano-Kanashiro C, Calderon-Vazquez C, Ibarra-Laclette E, Herrera-Estrella L, Simpson J: Analysis of gene expression and physiological responses in three Mexican maize landraces under drought stress and recovery irrigation. PLoS One 2009, 4:e7531.

4. Zwonitzer JC, Bubeck DM, Bhattramakki D, Goodman MM, Arellano C, BalintKurti PJ: Use of selection with recurrent backcrossing and QTL mapping to identify loci contributing to southern leaf blight resistance in a highly resistant maize line. Theor Appl Genet 2009, 118:911-925.

5. Pataky JK, Bohn MO, Lutz JD, Richter PM: Selection for quantitative trait loci associated with resistance to Stewart's wilt in sweet corn. Phytopathology 2008, 98:469-474

6. Wang G, Ellendorff U, Kemp B, Mansfield JW, Forsyth A, Mitchell K, Bastas K, Liu CM, Woods-Tör A, Zipfel C, de Wit PJ, Jones JD, Tör M, Thomma BP: A genome-wide functional investigation into the roles of receptor-like proteins in Arabidopsis. Plant Physiol 2008, 147:503-517.

7. van Vliet J, Oates NA, Whitelaw E: Epigenetic mechanisms in the context of complex diseases. Cell Mol Life Sci 2007, 64:1531-1538.

8. Stokes TL, Kunkel BN, Richards EJ: Epigenetic variation in Arabidopsis disease resistance. Genes Dev 2002, 16:171-182.

9. Hitchins MP: Inheritance of epigenetic aberrations (constitutional epimutations) in cancer susceptibility. Adv Genet 2010, 70:201-243.
10. Alvarez ME, Nota F, Cambiagno DA: Epigenetic control of plant immunity. Mol Plant Pathol 2010, 11:563-576.

11. Holliday R: The inheritance of epigenetic defects. Science 1987, 238:163-170.

12. Nicolson GL: Cell surface molecules and tumor metastasis. Regulation of metastatic phenotypic diversity. Exp Cell Res 1984, 150:3-22.

13. Ferluga J: Possible organ and age-related epigenetic factors in Huntington's disease and colorectal carcinoma. Med Hypotheses 1989, 29:51-54.

14. Bjornsson HT, Fallin MD, Feinberg AP: An integrated epigenetic and genetic approach to common human disease. Trends Genet 2004, 20:350-358.

15. Mehler MF: Epigenetic principles and mechanisms underlying nervous system functions in health and disease. Prog Neurobiol 2008, 86:305-341.

16. Graff J, Mansuy IM: Epigenetic codes in cognition and behaviour. Behav Brain Res 2008, 192:70-87.

17. Dolinoy DC, Huang D, Jirtle RL: Maternal nutrient supplementation counteracts bisphenol A-induced DNA hypomethylation in early development. Proc Natl Acad Sci U S A 2007, 104:13056-13061.

18. Cropley JE, Suter CM, Beckman KB, Martin DI: CpG methylation of a silent controlling element in the murine Avy allele is incomplete and unresponsive to methyl donor supplementation. PLoS One 2010, 5:e9055.

19. Meagher RB: The evolution of epitype. Plant Cell 2010, 22:1658-1666.

20. Slatkin M: Epigenetic inheritance and the missing heritability problem. Genetics 2009, 182:845-850.

21. Martin C, Zhang Y: Mechanisms of epigenetic inheritance. Curr Opin Cell Biol 2007, 19:266-272.

22. Johannes F, Porcher E, Teixeira FK, Saliba-Colombani V, Simon M, Agier N, Bulski A, Albuisson J, Heredia F, Audigier P, Bouchez D, Dillmann C, Guerche $P$, Hospital F, Colot V: Assessing the impact of transgenerational epigenetic variation on complex traits. PLOS Genet 2009, 5:e1000530.

23. Jablonka E, Raz G: Transgenerational epigenetic inheritance: prevalence, mechanisms, and implications for the study of heredity and evolution. Q Rev Biol 2009, 84:131-176.

24. Whitelaw NC, Whitelaw E: Transgenerational epigenetic inheritance in health and disease. Curr Opin Genet Dev 2008, 18:273-279.

25. Xing Y, Shi S, Le L, Lee CA, Silver-Morse L, Li WX: Evidence for transgenerational transmission of epigenetic tumor susceptibility in Drosophila. PLoS Genet 2007, 3:1598-1606.

26. Rakyan V, Whitelaw E: Transgenerational epigenetic inheritance. Curr Biol 2003, 13:R6

27. Morgan DK, Whitelaw E: The case for transgenerational epigenetic inheritance in humans. Mamm Genome 2008, 19:394-397.

28. Febbo PG: Epigenetic events highlight the challenge of validating prognostic biomarkers during the clinical and biologic evolution of prostate cancer. J Clin Oncol 2009, 27:3088-3090.

29. Haslberger A, Varga F, Karlic H: Recursive causality in evolution: a model for epigenetic mechanisms in cancer development. Med Hypotheses 2006, 67:1448-1454

30. Mills J, Hricik T, Siddiqi S, Matushansky I: Chromatin structure predicts epigenetic therapy responsiveness in sarcoma. Mol Cancer Ther 2011, 10:313-324.

31. King GJ, Amoah S, Kurup S: Exploring and exploiting epigenetic variation in crops. Genome 2010, 53:856-868.

32. Long Y, Xia W, Li R, Wang J, Shao M, Feng J, King GJ, Meng J: Epigenetic QTL mapping in Brassica napus. Genetics 2011, 189:1093-1102.

33. Jullien PE, Berger F: Gamete-specific epigenetic mechanisms shape genomic imprinting. Curr Opin Plant Biol 2009, 12:637-642.

34. Haig D: The (dual) origin of epigenetics. Cold Spring Harb Symp Quant Biol 2004, 69:67-70.

35. Hoekenga OA, Muszynski MG, Cone KC: Developmental patterns of chromatin structure and DNA methylation responsible for epigenetic expression of a maize regulatory gene. Genetics 2000, 155:1889-1902.

36. Waddington $\mathrm{CH}$ : Chapter 2. The Cybernetics of Development. In The strategy of the genes: A Discussion of Some Aspects of Theoretical Biology. London: Ruskin House, George Allen \& Unwin LTD; 1957.

37. Beisson J, Sonneborn TM: Cytoplasmic inheritance of the organization of the cell cortex in Paramecium aurelia. Proc Natl Acad Sci U S A 1965, 53:275-282

38. Verstrepen KJ, Fink GR: Genetic and epigenetic mechanisms underlying cell-surface variability in protozoa and fungi. Annu Rev Genet 2009, 43:1-24 
39. Nanney DL: Epigenetic control systems. Proc Natl Acad Sci U S A 1958, 44:712-717.

40. Hardy KM, Kirschmann DA, Seftor EA, Margaryan NV, Postovit LM, Strizzi L, Hendrix MJ: Regulation of the embryonic morphogen Nodal by Notch4 facilitates manifestation of the aggressive melanoma phenotype. Cancer Res 2010, 70:10340-10350.

41. Daxinger $L$, Whitelaw E: Transgenerational epigenetic inheritance: more questions than answers. Genome Res 2010, 20:1623-1628.

42. Menon DU, Meller VH: Germ line imprinting in Drosophila: epigenetics in search of function. Fly (Austin) 2010, 4:48-52.

43. Lange UC, Schneider R: What an epigenome remembers. Bioessays 2010, 32:659-668.

44. Ho DH, Burggren WW: Epigenetics and transgenerational transfer: a physiological perspective. J Exp Biol 2010, 213:3-16.

45. Youngson NA, Whitelaw E: Transgenerational epigenetic effects. Annu Rev Genomics Hum Genet 2008, 9:233-257.

46. Margueron R, Reinberg D: Chromatin structure and the inheritance of epigenetic information. Nat Rev Genet 2010, 11:285-296.

47. Wen B, Wu H, Shinkai Y, Irizarry RA, Feinberg AP: Large histone H3 lysine 9 dimethylated chromatin blocks distinguish differentiated from embryonic stem cells. Nat Genet 2009, 41:246-250.

48. Sass GL, Pannuti A, Lucchesi JC: Male-specific lethal complex of Drosophila targets activated regions of the $\mathrm{X}$ chromosome for chromatin remodeling. Proc Natl Acad Sci U S A 2003, 100:8287-8291.

49. Kang JK, Park KW, Chung YG, You JS, Kim YK, Lee SH, Hong SP, Choi KM, Heo KN, Seol JG, Lee JH, Jin DI, Park CS, Seo JS, Lee HW, Han JW: Coordinated change of a ratio of methylated $\mathrm{H} 3$-lysine 4 or acetylated $\mathrm{H} 3$ to acetylated $\mathrm{H} 4$ and DNA methylation is associated with tissue-specific gene expression in cloned pig. Exp Mol Med 2007 39:84-96.

50. Morgan DK, Whitelaw E: The role of epigenetics in mediating environmental effects on phenotype. Nestle Nutr Workshop Ser Pediatr Program 2009, 63:109-117. Discussion 117-109, 259-168.

51. Cortese R, Krispin M, Weiss G, Berlin K, Eckhardt F: DNA methylation profiling of pseudogene-parental gene pairs and two gene families. Genomics 2008, 91:492-502.

52. Clarke NF, Waddell LB, Cooper ST, Perry M, Smith RL, Kornberg AJ, Munton F, Lillis S, Straub V, Bushby K, Guglieri M, King MD, Farrell MA, Marty I, Lunardi J, Monnier N, North KN: Recessive mutations in RYR1 are a common cause of congenital fiber type disproportion. Hum Mutat 2010, 31:E1544-E1550.

53. Robinson RL, Carpenter D, Halsall PJ, lles DE, Booms P, Steele D, Hopkins PM, Shaw MA: Epigenetic allele silencing and variable penetrance of malignant hyperthermia susceptibility. Br J Anaesth 2009, 103:220-225.

54. Wilmshurst JM, Lillis S, Zhou H, Pillay K, Henderson H, Kress W, Müller CR, Ndondo A, Cloke V, Cullup T, Bertini E, Boennemann C, Straub V, Quinlivan R, Dowling JJ, Al-Sarraj S, Treves S, Abbs S, Manzur AY, Sewry CA, Muntoni F, Jungbluth $\mathrm{H}: R Y R 1$ mutations are a common cause of congenital myopathies with central nuclei. Ann Neurol 2010, 68:717-726.

55. Zhou H, Lillis S, Loy RE, Ghassemi F, Rose MR, Norwood F, Mills K, Al-Sarraj S, Lane RJ, Feng L, Matthews E, Sewry CA, Abbs S, Buk S, Hanna M, Treves S, Dirksen RT, Meissner G, Muntoni F, Jungbluth H: Multi-minicore disease and atypical periodic paralysis associated with novel mutations in the skeletal muscle ryanodine receptor (RYR1) gene. Neuromuscul Disord 2010, 20:166-173.

56. Zhou $H$, Brockington $M$, Jungbluth $H$, Monk D, Stanier $P$, Sewry CA, Moore $\mathrm{GE}$, Muntoni F: Epigenetic allele silencing unveils recessive RYR1 mutations in core myopathies. Am J Hum Genet 2006, 79:859-868.

57. Chen H, Taylor NP, Sotamaa KM, Mutch DG, Powell MA, Schmidt AP, Feng S, Hampel HL, de la Chapelle A, Goodfellow PJ: Evidence for heritable predisposition to epigenetic silencing of MLH1. Int J Cancer 2007, 120:1684-1688.

58. Hitchins MP, Wong JJ, Suthers G, Suter CM, Martin DI, Hawkins NJ, Ward RL: Inheritance of a cancer-associated MLH1 germ-line epimutation. N Engl J Med 2007, 356:697-705.

59. Vilar E, Scaltriti M, Balmana J, Saura C, Guzman M, Arribas J, Baselga J, Tabernero J: Microsatellite instability due to $h M L H 1$ deficiency is associated with increased cytotoxicity to irinotecan in human colorectal cancer cell lines. Br J Cancer 2008, 99:1607-1612.
60. Lin JC, Jeong S, Liang G, Takai D, Fatemi M, Tsai YC, Egger G, Gal-Yam EN, Jones PA: Role of nucleosomal occupancy in the epigenetic silencing of the MLH1 CpG island. Cancer Cell 2007, 12:432-444.

61. Ren F, Wang D, Jiang Y: Epigenetic inactivation of $h M L H 1$ in the malignant transformation of ovarian endometriosis. Arch Gynecol Obstet 2012, 285:215-221.

62. Wu PY, Fan YM, Wang YP: Germ-line epimutations and human cancer. Ai Zheng 2009, 28:1236-1242.

63. Morgan HD, Sutherland HG, Martin DI, Whitelaw E: Epigenetic inheritance at the agouti locus in the mouse. Nat Genet 1999, 23:314-318.

64. Martin DI, Cropley JE, Suter CM: Environmental influence on epigenetic inheritance at the Avy allele. Nutr Rev 2008, 66(Suppl 1):S12-S14

65. Morgan HD, Jin XL, Li A, Whitelaw E, O'Neill C: The culture of zygotes to the blastocyst stage changes the postnatal expression of an epigentically labile allele, agouti viable yellow, in mice. Biol Reprod 2008, 79:618-623.

66. Perry WL, Copeland NG, Jenkins NA: The molecular basis for dominant yellow agouti coat color mutations. Bioessays 1994, 16:705-707.

67. Michaud EJ, van Vugt MJ, Bultman SJ, Sweet HO, Davisson MT, Woychik RP: Differential expression of a new dominant agouti allele (Aiapy) is correlated with methylation state and is influenced by parental lineage. Genes Dev 1994, 8:1463-1472.

68. Ruvinsky A, Flood WD, Zhang T, Costantini F: Unusual inheritance of the AxinFu mutation in mice is associated with widespread rearrangements in the proximal region of chromosome 17. Genet Res 2000, 76:135-147.

69. Vasicek TJ, Zeng L, Guan XJ, Zhang T, Costantini F, Tilghman SM: Two dominant mutations in the mouse fused gene are the result of transposon insertions. Genetics 1997, 147:777-786.

70. Rakyan VK, Chong S, Champ ME, Cuthbert PC, Morgan HD, Luu KV, Whitelaw E: Transgenerational inheritance of epigenetic states at the murine Axin(Fu) allele occurs after maternal and paternal transmission. Proc Natl Acad Sci U S A 2003, 100:2538-2543.

71. Waterland RA, Dolinoy DC, Lin JR, Smith CA, Shi X, Tahiliani KG: Maternal methyl supplements increase offspring DNA methylation at Axin Fused. Genesis 2006, 44:401-406.

72. Fernandez-Gonzalez R, Ramirez MA, Pericuesta E, Calle S, Gutierrez-Adan A: Histone modifications at the blastocyst Axin 1FU locus mark the heritability of in vitro culture-induced epigenetic alterations in mice. Biol Reprod 2010, 83:720-727.

73. Manning K, Tor M, Poole M, Hong Y, Thompson AJ, King GJ, Giovannoni JJ, Seymour GB: A naturally occurring epigenetic mutation in a gene encoding an SBP-box transcription factor inhibits tomato fruit ripening. Nat Genet 2006, 38:948-952.

74. Gustafsson A: Linnaeus' peloria: the history of a monster. TAG 1979 54:241-248.

75. Cubas $P$, Vincent $C$, Coen E: An epigenetic mutation responsible for natural variation in floral symmetry. Nature 1999, 401:157-161.

76. Li B, Carey M, Workman JL: The role of chromatin during transcription. Cell 2007, 128:707-719

77. Katz DJ, Edwards TM, Reinke V, Kelly WG: A C. elegans LSD1 demethylase contributes to germline immortality by reprogramming epigenetic memory. Cell 2009, 137:308-320.

78. Arico JK, Katz DJ, van der Vlag J, Kelly WG: Epigenetic patterns maintained in early Caenorhabditis elegans embryos can be established by gene activity in the parental germ cells. PLoS Genet 2011, 7:e1001391.

79. Agger K, Christensen J, Cloos PA, Helin K: The emerging functions of histone demethylases. Curr Opin Genet Dev 2008, 18:159-168.

80. Zhou X, Ma H: Evolutionary history of histone demethylase families: distinct evolutionary patterns suggest functional divergence. BMC Evol Biol 2008, 8:294.

81. Jeong $J H$, Song $H R$, Ko JH, Jeong YM, Kwon YE, Seol JH, Amasino RM, Noh B, Noh YS: Repression of FLOWERING LOCUS T chromatin by functionally redundant histone $\mathrm{H} 3$ lysine 4 demethylases in Arabidopsis. PLOS One 2009, 4:e8033.

82. Reinders J, Wulff BB, Mirouze M, Mari-Ordonez A, Dapp M, Rozhon W, Bucher $E$, Theiler G, Paszkowski J: Compromised stability of DNA methylation and transposon immobilization in mosaic Arabidopsis epigenomes. Genes Dev 2009, 23:939-950.

83. Richards EJ: Quantitative epigenetics: DNA sequence variation need not apply. Genes Dev 2009, 23:1601-1605. 
84. Soppe WJ, Jacobsen SE, Alonso-Blanco C, Jackson JP, Kakutani T, Koornneef $M$, Peeters AJ: The late flowering phenotype of fwa mutants is caused by gain-of-function epigenetic alleles of a homeodomain gene. Mol Cell 2000, 6:791-802.

85. Hajkova P, Erhardt S, Lane N, Haaf T, El-Maarri O, Reik W, Walter J, Surani MA: Epigenetic reprogramming in mouse primordial germ cells. Mech Dev 2002, 117:15-23.

86. Popp C, Dean W, Feng S, Cokus SJ, Andrews S, Pellegrini M, Jacobsen SE, Reik W: Genome-wide erasure of DNA methylation in mouse primordial germ cells is affected by AID deficiency. Nature 2010, 463:1101-1105.

87. Monk M, Boubelik M, Lehnert S: Temporal and regional changes in DNA methylation in the embryonic, extraembryonic and germ cell lineages during mouse embryo development. Development 1987, 99:371-382.

88. Feng S, Jacobsen SE, Reik W: Epigenetic reprogramming in plant and animal development. Science 2010, 330:622-627.

89. Bourc'his D, Voinnet O: A small-RNA perspective on gametogenesis, fertilization, and early zygotic development. Science 2010, 330:617-622.

90. Richards EJ: Inherited epigenetic variation-revisiting soft inheritance. Nat Rev Genet 2006, 7:395-401.

91. Lippman Z, Gendrel AV, Black M, Vaughn MW, Dedhia N, McCombie WR, Lavine K, Mittal V, May B, Kasschau KD, Carrington JC, Doerge RW, Colot V, Martienssen R: Role of transposable elements in heterochromatin and epigenetic control. Nature 2004, 430:471-476.

92. Schmitz RJ, Schultz MD, Lewsey MG, O'Malley RC, Urich MA, Libiger O, Schork NJ, Ecker JR: Transgenerational epigenetic instability is a source of novel methylation variants. Science 2011, 334:369-373.

93. Lejeune $\mathrm{E}$, Allshire RC: Common ground: small RNA programming and chromatin modifications. Curr Opin Cell Biol 2011, 23:258-265.

94. Teixeira FK, Heredia F, Sarazin A, Roudier F, Boccara M, Ciaudo C, Cruaud C, Poulain J, Berdasco M, Fraga MF, Voinnet O, Wincker P, Esteller M, Colot V: A role for RNAi in the selective correction of DNA methylation defects. science 2009, 323:1600-1604.

95. Verdel A, Vavasseur A, Le Gorrec M, Touat-Todeschini L: Common themes in siRNA-mediated epigenetic silencing pathways. Int J Dev Biol 2009, 53:245-257.

96. Hajkova P, Ancelin K, Waldmann T, Lacoste N, Lange UC, Cesari F, Lee C, Almouzni G, Schneider R, Surani MA: Chromatin dynamics during epigenetic reprogramming in the mouse germ line. Nature 2008, 452:877-881.

97. van der Heijden GW, Castaneda J, Bortvin A: Bodies of evidence compartmentalization of the piRNA pathway in mouse fetal prospermatogonia. Curr Opin Cell Biol 2010, 22:752-757.

98. Hajkova P: Epigenetic reprogramming in the germline: towards the ground state of the epigenome. Philos Trans R Soc Lond B Biol Sci 2011 366:2266-2273.

99. Boiani M, Eckardt S, Leu NA, Scholer HR, McLaughlin KJ: Pluripotency deficit in clones overcome by clone-clone aggregation: epigenetic complementation? EMBO J 2003, 22:5304-5312.

100. Whitworth KM, Prather RS: Somatic cell nuclear transfer efficiency: how can it be improved through nuclear remodeling and reprogramming? Mol Reprod Dev 2010, 77:1001-1015

101. Balbach ST, Esteves TC, Houghton FD, Siatkowski M, Pfeiffer MJ, Tsurumi C, Kanzler B, Fuellen G, Boiani M: Nuclear reprogramming: kinetics of cell cycle and metabolic progression as determinants of success. PLoS One 2012, 7:e35322.

102. Hosseini SM, Hajian M, Forouzanfar M, Moulavi F, Abedi P, Asgari V, Tanhaei S, Abbasi H, Jafarpour F, Ostadhosseini S, Karamali F, Karbaliaie K, Baharvand $\mathrm{H}$, Nasr-Esfahani MH: Enucleated ovine oocyte supports human somatic cells reprogramming back to the embryonic stage. Cell Reprogram 2012, 14:155-163.

103. Noggle S, Fung HL, Gore A, Martinez $H$, Satriani KC, Prosser R, Oum K, Paull D, Druckenmiller S, Freeby M, Greenberg E, Zhang K, Goland R, Sauer MV, Leibel RL, Egli D: Human oocytes reprogram somatic cells to a pluripotent state. Nature 2011, 478:70-75

104. Pan G, Wang T, Yao $H$, Pei D: Somatic cell reprogramming for regenerative medicine: SCNT vs. iPS cells. Bioessays 2012, 34:472-476

105. Niemann H, Carnwath JW, Herrmann D, Wieczorek G, Lemme E, Lucas-Hahn A, Olek S: DNA methylation patterns reflect epigenetic reprogramming in bovine embryos. Cell Reprogram 2010, 12:33-42.
106. Cui XS, Zhang DX, Ko YG, Kim NH: Aberrant epigenetic reprogramming of imprinted microRNA-127 and Rt11 in cloned mouse embryos. Biochem Biophys Res Commun 2009, 379:390-394

107. Su J, Wang Y, Li R, Peng H, Hua S, Li Q, Quan F, Guo Z, Zhang Y: Oocytes selected using $B C B$ staining enhance nuclear reprogramming and the in vivo development of SCNT embryos in cattle. PLoS One 2012, 7:e36181.

108. Wang F, Kou Z, Zhang Y, Gao S: Dynamic reprogramming of histone acetylation and methylation in the first cell cycle of cloned mouse embryos. Biol Reprod 2007, 77:1007-1016.

109. Jullien J, Pasque V, Halley-Stott RP, Miyamoto K, Gurdon JB: Mechanisms of nuclear reprogramming by eggs and oocytes: a deterministic process? Nat Rev Mol Cell Biol 2011, 12:453-459.

110. Trifonov EN: Sequence-dependent deformational anisotropy of chromatin DNA. Nucleic Acids Res 1980, 8:4041-4053.

111. Trifonov EN, Sussman JL: The pitch of chromatin DNA is reflected in its nucleotide sequence. Proc Natl Acad Sci U S A 1980, 77:3816-3820.

112. Frenkel ZM, Bettecken T, Trifonov EN: Nucleosome DNA sequence structure of isochores. BMC Genomics 2011, 12:203.

113. Trifonov EN: Nucleosome positioning by sequence, state of the art and apparent finale. J Biomol Struct Dyn 2010, 27:741-746.

114. Rapoport AE, Frenkel ZM, Trifonov EN: Nucleosome positioning pattern derived from oligonucleotide compositions of genomic sequences. J Biomol Struct Dyn 2011, 28:567-574.

115. Zofall M, Persinger J, Kassabov SR, Bartholomew B: Chromatin remodeling by ISW2 and SWI/SNF requires DNA translocation inside the nucleosome. Nat Struct Mol Biol 2006, 13:339-346.

116. Albert I, Mavrich TN, Tomsho LP, Qi J, Zanton SJ, Schuster SC, Pugh BF: Translational and rotational settings of H2A.Z nucleosomes across the Saccharomyces cerevisiae genome. Nature 2007, 446:572-576.

117. Chodavarapu RK, Feng S, Bernatavichute YV, Chen PY, Stroud H, Yu Y, Hetzel JA, Kuo F, Kim J, Cokus SJ, Casero D, Bernal M, Huijser P, Clark AT, Krämer U, Merchant SS, Zhang X, Jacobsen SE, Pellegrini M: Relationship between nucleosome positioning and DNA methylation. Nature 2010, 466:388-392.

118. Cui F, Zhurkin VB: Structure-based analysis of DNA sequence patterns guiding nucleosome positioning in vitro. J Biomol Struct Dyn 2010, 27:821-841

119. Schones DE, Cui K, Cuddapah S, Roh TY, Barski A, Wang Z, Wei G, Zhao K: Dynamic regulation of nucleosome positioning in the human genome. Cell 2008, 132:887-898

120. Meneghini MD, Wu M, Madhani HD: Conserved histone variant H2A.Z protects euchromatin from the ectopic spread of silent heterochromatin. Cell 2003, 112:725-736.

121. Li B, Pattenden SG, Lee D, Gutierrez J, Chen J, Seidel C, Gerton J, Workman $J$ : Preferential occupancy of histone variant $\mathrm{H} 2 \mathrm{AZ}$ at inactive promoters influences local histone modifications and chromatin remodeling. Proc Natl Acad Sci U S A 2005, 102:18385-18390.

122. Deal RB, Topp CN, McKinney EC, Meagher RB: Repression of flowering in Arabidopsis requires activation of FLOWERING LOCUS C expression by the histone variant H2A.Z. Plant Cell 2007, 19:74-83.

123. Gent J, Schneider KL, Topp CN, Rodriguez C, Presting GG, Dawe RK: Distinct influences of tandem repeats and retrotransposons on $\mathrm{CENH} 3$ nucleosome positioning. Epigenetics Chromatin 2011, 4:3.

124. Barski A, Cuddapah S, Cui K, Roh TY, Schones DE, Wang Z, Wei G, Chepelev I, Zhao K: High-resolution profiling of histone methylations in the human genome. Cell 2007, 129:823-837.

125. Zheng D: Asymmetric histone modifications between the original and derived loci of human segmental duplications. Genome Biol 2008, 9:R105.

126. Margueron R, Trojer P, Reinberg D: The key to development: interpreting the histone code? Curr Opin Genet Dev 2005, 15:163-176.

127. Hammoud SS, Nix DA, Zhang H, Purwar J, Carrell DT, Cairns BR: Distinctive chromatin in human sperm packages genes for embryo development. Nature 2009, 460:473-478.

128. Dillon N: Gene regulation and large-scale chromatin organization in the nucleus. Chromosome Res 2006, 14:117-126.

129. Murrell A, Heeson S, Reik W: Interaction between differentially methylated regions partitions the imprinted genes Igf2 and $\mathrm{H} 19$ into parent-specific chromatin loops. Nat Genet 2004, 36:889-893.

130. Teller K, Solovei I, Buiting K, Horsthemke B, Cremer T: Maintenance of imprinting and nuclear architecture in cycling cells. Proc Natl Acad Sci U S A 2007, 104:14970-14975. 
131. Gaillard C, Borde C, Gozlan J, Marechal V, Strauss F: A high-sensitivity method for detection and measurement of HMGB1 protein concentration by high-affinity binding to DNA hemicatenanes. PLoS One 2008, 3:e2855.

132. Jaouen S, de Koning L, Gaillard C, Muselikova-Polanska E, Stros M, Strauss F: Determinants of specific binding of HMGB1 protein to hemicatenated DNA loops. J Mol Biol 2005, 353:822-837.

133. Gondor A, Ohlsson R: Chromosome crosstalk in three dimensions. Nature 2009, 461:212-217.

134. Deng W, Blobel GA: Do chromatin loops provide epigenetic gene expression states? Curr Opin Genet Dev 2010, 20:548-554.

135. Sumida N, Ohlsson R: Chromosomal networks as mediators of epigenetic states: the maternal genome connection. Epigenetics 2011, 5:297-300.

136. Riggs AD, Martienssen RA, Russo VEA: Introduction. In Epigenetic mechanisms of gene regulation, Volume 32. Edited by Russo VEA. Cold Spring Harbor: Cold Spring Harbor Laboratory Press; 1996:1-4.

137. Wang X, Zhu H, Snieder H, Su S, Munn D, Harshfield G, Maria BL, Dong Y, Treiber F, Gutin B, Shi H: Obesity related methylation changes in DNA of peripheral blood leukocytes. BMC Med 2010, 8:87.

138. Jeffries MA, Dozmorov M, Tang Y, Merrill JT, Wren JD, Sawalha AH: Genome-wide DNA methylation patterns in CD4+ T cells from patients with systemic lupus erythematosus. Epigenetics 2011, 6:593-601.

139. Luna E, Bruce TJ, Roberts MR, Flors V, Ton J: Next-generation systemic acquired resistance. Plant Physiol 2012, 158:844-853.

140. Yazbek SN, Spiezio SH, Nadeau JH, Buchner DA: Ancestral paternal genotype controls body weight and food intake for multiple generations. Hum Mol Genet 2010, 19:4134-4144.

141. McDevitt MA: Clinical applications of epigenetic markers and epigenetic profiling in myeloid malignancies. Semin Oncol 2012, 39:109-122

142. Radpour R, Kohler C, Haghighi MM, Fan AX, Holzgreve W, Zhong XY: Methylation profiles of 22 candidate genes in breast cancer using highthroughput MALDI-TOF mass array. Oncogene 2009, 28:2969-2978.

143. Deng D, Liu Z, Du Y: Epigenetic alterations as cancer diagnostic, prognostic, and predictive biomarkers. Adv Genet 2010, 71:125-176.

144. Javierre BM, Fernandez AF, Richter J, Al-Shahrour F, Martin-Subero Jl, Rodriguez-Ubreva J, Berdasco M, Fraga MF, O'Hanlon TP, Rider LG, Jacinto FV, Lopez-Longo FJ, Dopazo J, Forn M, Peinado MA, Carreño L, Sawalha AH, Harley JB, Siebert R, Esteller M, Miller FW, Ballestar E: Changes in the pattern of DNA methylation associate with twin discordance in systemic lupus erythematosus. Genome Res 2010, 20:170-179.

145. Tilgner K, Atkinson SP, Yung S, Golebiewska A, Stojkovic M, Moreno R, Lako $M$, Armstrong L: Expression of GFP under the control of the RNA helicase VASA permits fluorescence-activated cell sorting isolation of human primordial germ cells. Stem Cells 2010, 28:84-92.

146. Merbs SL, Khan MA, Hackler L Jr, Oliver VF, Wan J, Qian J, Zack DJ: Cellspecific DNA methylation patterns of retina-specific genes. PLoS One 2012, 7:e32602.

147. Deal RB, Henikoff S: A simple method for gene expression and chromatin profiling of individual cell types within a tissue. Dev Cell 2010, 18:1030-1040

148. Deal RB, Henikoff S: The INTACT method for cell type-specific gene expression and chromatin profiling in Arabidopsis thaliana. Nat Protoc 2011, 6:56-68.

149. Jiang G, Zheng L, Pu J, Mei H, Zhao J, Huang K, Zeng F, Tong Q: Small RNAs targeting transcription start site induce heparanase silencing through interference with transcription initiation in human cancer cells. PLoS One 2012, 7:e31379.

150. Jauvion V, Rivard M, Bouteiller N, Elmayan T, Vaucheret H: RDR2 partially antagonizes the production of RDR6-dependent siRNA in sense transgene-mediated PTGS. PLOS One 2012, 7:e29785.

151. Matzke M, Kanno T, Daxinger L, Huettel B, Matzke AJ: RNA-mediated chromatin-based silencing in plants. Curr Opin Cell Biol 2009, 21:367-376. doi:10.1186/1756-8935-5-11

Cite this article as: Meagher and Müssar: The influence of DNA

sequence on epigenome-induced pathologies. Epigenetics \& Chromatin 2012 5:11

\section{Submit your next manuscript to BioMed Central and take full advantage of:}

- Convenient online submission

- Thorough peer review

- No space constraints or color figure charges

- Immediate publication on acceptance

- Inclusion in PubMed, CAS, Scopus and Google Scholar

- Research which is freely available for redistribution 